\title{
Low-Frequency AC Power Transmission and Distribution for Subsea Application Using Hexverter
}

\author{
Muhammad Umair Safder ${ }^{1}$, Syed Tahir Hussain Rizvi ${ }^{2, *}$, Yongqing Meng ${ }^{3}$, \\ Muhammad Yaqoob Javed ${ }^{1} \mathbb{D}$, Mujtaba Hussain Jaffery ${ }^{1}$ and Muhammad Sarmad Hassan ${ }^{1}$ \\ 1 Electrical and Computer Engineering Department, COMSATS University Islamabad, Lahore Campus, \\ Lahore, Punjab 54000, Pakistan; umairsafder@cuilahore.edu.pk (M.U.S.); \\ yaqoob.javed@cuilahore.edu.pk (M.Y.J.); m.jaffery@cuilahore.edu.pk (M.H.J.); \\ sarmad.hassan@cuilahore.edu.pk (M.S.H.) \\ 2 Department of Computer Engineering, The University of Lahore, Lahore 54000, Pakistan \\ 3 Electrical Engineering School, Xi'an Jiaotong University, Xi'an 710049, China; mengyq@mail.xjtu.edu.cn \\ * Correspondence: tahir.hussain@dce.uol.edu.pk; Tel.: +92-332-485-6585
}

Received: 19 October 2019; Accepted: 12 December 2019; Published: 1 January 2020

check for updates

\begin{abstract}
Environmental goals set by world leaders to normalize climate changes are quite difficult to achieve without renewable power generation and suitable transmission technologies like low-frequency AC transmission (LFAC). The LFAC is nowadays becoming a popular choice for long-distance power transmission due to its high efficiency and low losses. This research work investigates the feasibility of employing the LFAC system for subsea transmission and distribution of $58 \mathrm{MW}$ power. In this paper, the simulation model of the LFAC-based subsea transmission and distribution system is presented. This model is composed of several parts such as hexverter as a frequency converter, where a novel control strategy to optimize its zero-sequence circulating current is employed. Detailed mathematical modeling based on active, reactive power constraints and DQ transformation is performed to achieve the control strategy for zero-sequence current optimization. An offshore wind farm is proposed to be integrated with the LFAC subsea system to fulfill the compatibility requirements of the system. The control system of both the grid side and the machine-side inverter of the wind farm is designed to eliminate the real-time disturbances such as wind speed fluctuations and harmonics due to heavy inductive load operating at $16 \mathrm{~Hz}$. To drive the subsea pump, a vector control-based variable-speed drive is employed for the heavy induction motor. A $5 \mathrm{MW}, 16 \mathrm{~Hz}$ RL load is also added in the model to analyze the effect of general-purpose load. Each component of this system is carefully designed to make it as close to real-time as possible. The whole system is designed for $16 \mathrm{~Hz}$ and is compared with the standard $50 \mathrm{~Hz}$ system to validate this design.
\end{abstract}

Keywords: subsea transmission and distribution (subsea T\&D system); LFAC; H-MMC (hexverter); variable-speed drive (VSD); wind farm integration; zero sequence current optimization

\section{Introduction}

There is an increasing demand for deep-water oil and gas production due to the depletion of existing oil and gas reserves. Long-distance power transmission and distribution is required for multiple subsea electrical loads [1]. Electric power can be transmitted and distributed over long distances either by direct current or alternating current. Subsea electrification is an important part of processing and controlling deep-water oil and gas production [2]. Subsea processing mainly includes pumping, compression and separation that demand the deployment of equipment such as motors, switchgear, variable speed drives (VSDs) and power supplies near the loads (connected through wet and dry mate connectors) [3]. Subsea control requires electric actuators and valves for "All-Electric" 
trees and a reliable power supply for the communication and control at long step out distances [4]. The subsea processing system manipulates the well-stream between the host and the well-head.

Subsea processing applications include Hydrocarbon boosting (pumping), Separation systems, Raw seawater injection and Gas compression [2]. All these applications have some primary requirements that must be fulfilled to perform these operations, and these necessaries concerns are the distribution of high voltage power at long distance/low-frequency, advanced process monitoring and control, cost-efficient installation, maintenance and retrieval [1]. There has been rapid growth in the subsea oil and gas industry over the last several decades, as shown in Figure 1. Therefore, it is understandable how important it is to develop a system that is efficient and less costly for extracting oil and gas from the seabed, because the natural resources on the ground are decreasing day by day. Statoil operates approximately 480 subsea wells. In 2010, more than 50\% of Norwegian production was from subsea wells [5]. Subsea processing is a way of enabling new developments and increasing the recovery factor analysis of the economic feasibility of offshore wind farms (OWFs) connected with low-frequency alternating current (LFAC) transmission systems [6]. The purpose of explaining the oil processing system is to introduce the LFAC transmission and distribution system that can be used under the sea. In Europe, the LFAC system is now being used in the subsea processing system. Alternating current with a frequency of $50 \mathrm{~Hz}$ is suitable for shorter distances. This $50 \mathrm{~Hz}$ system is still feasible for longer distances of up to $80 \mathrm{~km}$ [7], but there will be greater losses and limited available power. High voltage direct current (HVDC) transmission is a promising solution, but still faces the problem related to the HVDC circuit breakers [8].

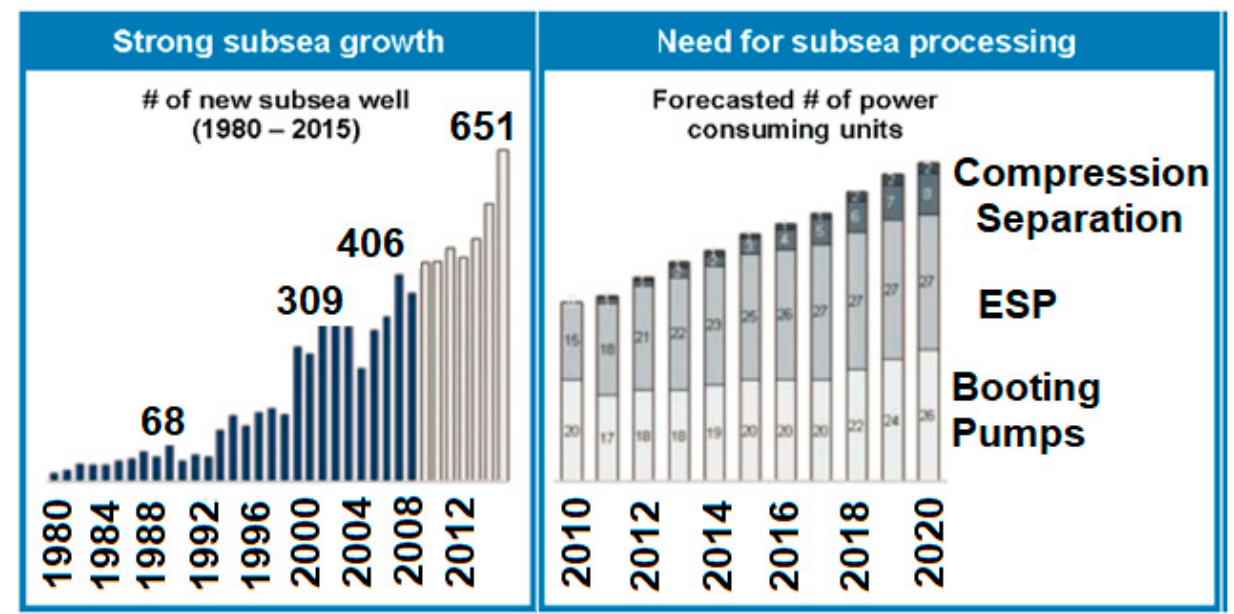

Figure 1. Subsea oil and gas growth.

The LFAC transmission system, sometimes also called fractional frequency transmission system (FFTS), works on low frequencies such as $16 \mathrm{~Hz}$ to transmit power under the sea. At this frequency, the losses associated with frequency will be minimized. These losses can either be due to the transmission line or the equipment under operation. The LFAC system provides the opportunity to receive the benefits of both $\mathrm{AC}$ and $\mathrm{DC}$, which cannot be provided individually by either AC or DC systems [3]. AC can be step up or step down, but at low frequency, it can decrease the reactance losses and RL associated losses.

The purpose of this research paper is to introduce the whole LFAC transmission system and highlight its operational advantages. This system can transmit power over a longer distance with fewer losses, which can be useful for subsea transmission and distribution of power. The proposed system consists of a frequency converter named "hexverter" with zero-sequence current optimization [9-11], offshore windfarm integration, vector control-based subsea variable speed drive, and a $5 \mathrm{MW}$ induction motor to operate the pump. In this system, a $5 \mathrm{MW}$ RL load is employed for the purpose of maintaining heating and lighting. The hexverter takes power to convert its frequency and transmit that power 
through pi-connected transmission lines to the top-side transformer to step up to certain voltage levels to further send it to the subsea distribution transformer where the voltage level will be step down again for distribution purposes. Furthermore, a $20 \mathrm{MW}$ wind farm is integrated into the system to make the power rating of the system compatible with the same frequency, i.e., $16 \mathrm{~Hz}$. Details of hexverter control, VSD control and transmission line parameters along with motor specifications are discussed in the following sections.

As mentioned earlier, the LFAC provides the benefits of both AC and DC, but an optimized frequency converter is not available for this job. Several multi-modular converters (MMC) are available, but their topologies have issues like excessive semiconductor losses, circulating current losses, and the problem of heat handling. Active and reactive power regulation is also an issue to be considered in the selection of these converters.

The main contribution of this paper is the optimization of the frequency converter "hexverter" and the subsea transmission of power through LFAC. All parameters in our work are chosen following intense study of the subsea systems literature. Moreover, offshore wind farm integration and a vector control-based variable speed drive for the subsea motor are employed to increase the efficiency of the system [11-14].

The novel control strategy proposed in this paper is to optimize the zero-sequence current for the $16 \mathrm{~Hz}$ LFAC system. Researchers have proposed different strategies for the hexverter optimization, such as active power control, branch voltage control, inductance influence and control $[15,16]$, but no one has addressed the control strategy for zero-sequence current. Furthermore, a lot of work has also been done on offshore wind farm integration with LFAC and FFT systems interim of inverter control, converter control for the resonance contingency of long transmission lines and harmonics problem in inverters [17-20].

\section{Modeling of LFAC-Based Subsea T\&D Systems}

This section presents the details of our model. For the representation of the offshore system present on the land, the power source, frequency converter and a step-up transformer are used. For the undersea system, a transmission line (power and control cables) of approximately $100 \mathrm{~km}$ length and $850 \mathrm{~m}$ depth is chosen. A subsea step-down transformer is used to convert our low-frequency high voltage AC to the appropriate level voltage for the load. Moreover, for driving the pump and compressors, high-power subsea motors are employed. These motors are driven by the variable speed drive using the vector control method, and an RL load for the general-purpose undersea applications (e.g., lighting, heating and maintenance, etc.) is used.

Figure 2 presents the SIMULINK model of the proposed subsea T\&D system. As shown in Figure 2, an offshore wind farm model of $20 \mathrm{MW}$ capacity is integrated with the low-frequency AC system through the $5 \mathrm{~km}$ underwater transmission line with $850 \mathrm{~m}$ depth. The complete T\&D system is composed of different sections contributing to the realization of the system and to increase the effectiveness of it. A frequency converter is required for low-frequency AC transmission, and a hexverter is chosen for this purpose. The hexverter is very effective for frequency conversion due to its unique topology, and it is optimized further in this work by a novel control strategy in terms of its zero-sequence current. The transmission system for LFAC is also designed and a wind farm is added to support the system to meet the requirement of the power rating as it is an effective way to increase our power demand in the future. Less conversion is required for wind and to meet the LFAC criteria. 


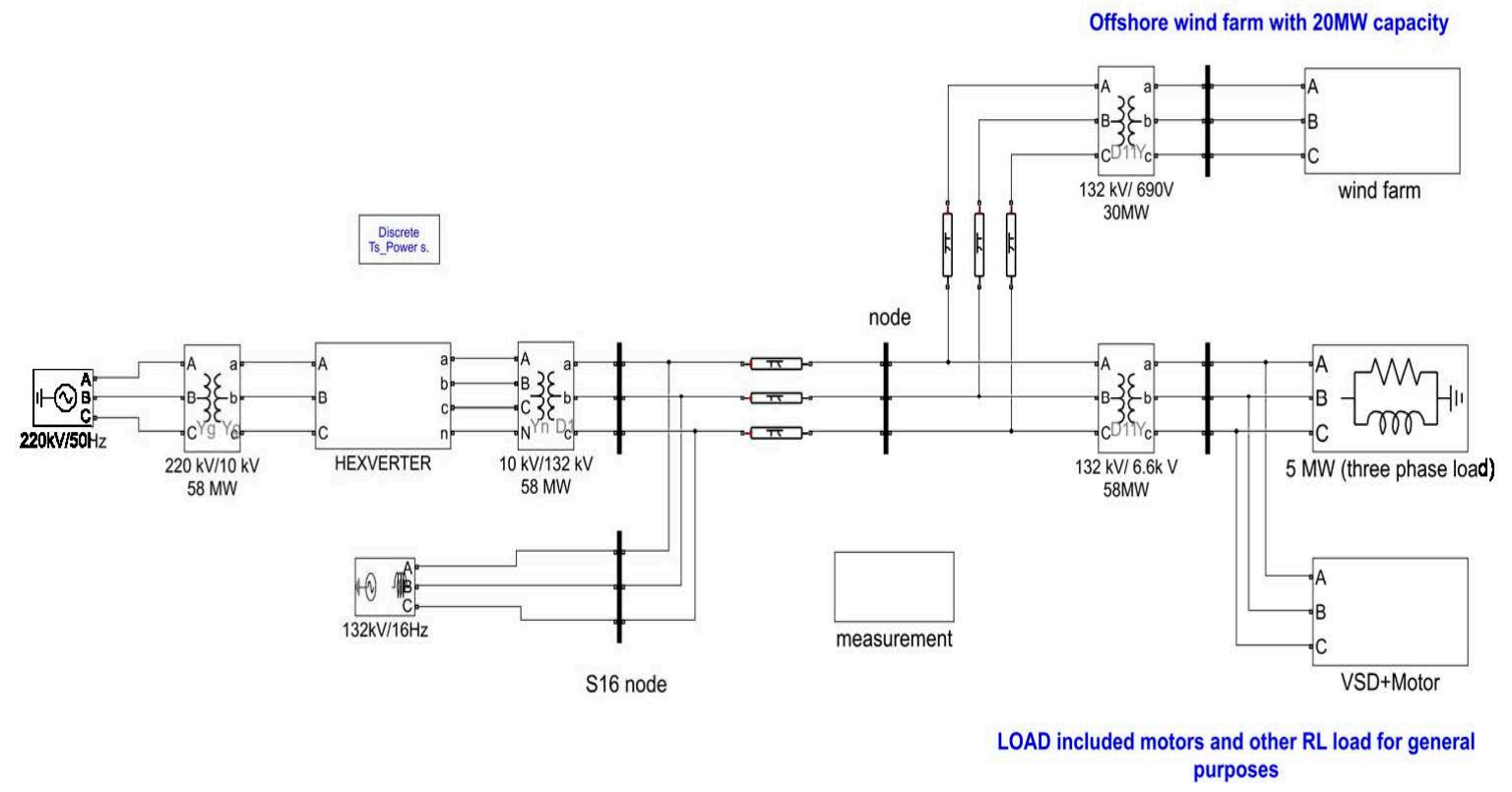

Figure 2. SIMULINK Model of Subsea T\&D System.

The transmitted power can then be used to drill the oil from the seabed. For this purpose, we designed a variable speed drive for a $5 \mathrm{MW}$ induction motor using the vector-controlled method, and a 5 MW RL load was employed for general purposes. Moreover, all equipment used in the distribution level was designed at $16 \mathrm{~Hz}$ frequency. Therefore, each block plays its part in the effectiveness of the whole system. In the following subsections, each part of the proposed system is discussed in detail.

\subsection{Hexverter Modeling and Its Control Strategy}

There are many converter topologies for high power applications. The modular multilevel converter, the modular multilevel matrix converter, and the hexagonal modular multilevel AC/AC converter (hexverter), are the most common among them. These converters have widely drawn the attention of scholars and industry experts [10], as they show substantial potential to be among the next generation of high-power high/medium-voltage power converters [11]. The selection of the most suitable converter from the other family members depends on the application and current/voltage ratings, as each member has its own characteristics with respect to performance and viability.

Lennart Baruschka and Axel Mertens of Hannover Leibniz University proposed a novel hexagonal modular multilevel AC/AC converter (hexverter), which can be used in high-voltage and high-power applications [12]. This topology structure is shown in Figure 3, and is used in our system. The fundamental concept of the hexagonal converter depends on the corresponding area in $[9,13]$. The responsibility of the hexagonal converter is to join the two three-phase systems, exchange power between them, and provide responsive energy to the associated system. It consists of alleged branches (or: groups, arms), where each of the six branches contains an H-bridge, sub-modules and an inductor. The hexagonal modular multi-level converter (hexverter) connects two 3-phase power systems, as shown in Figure 3. 


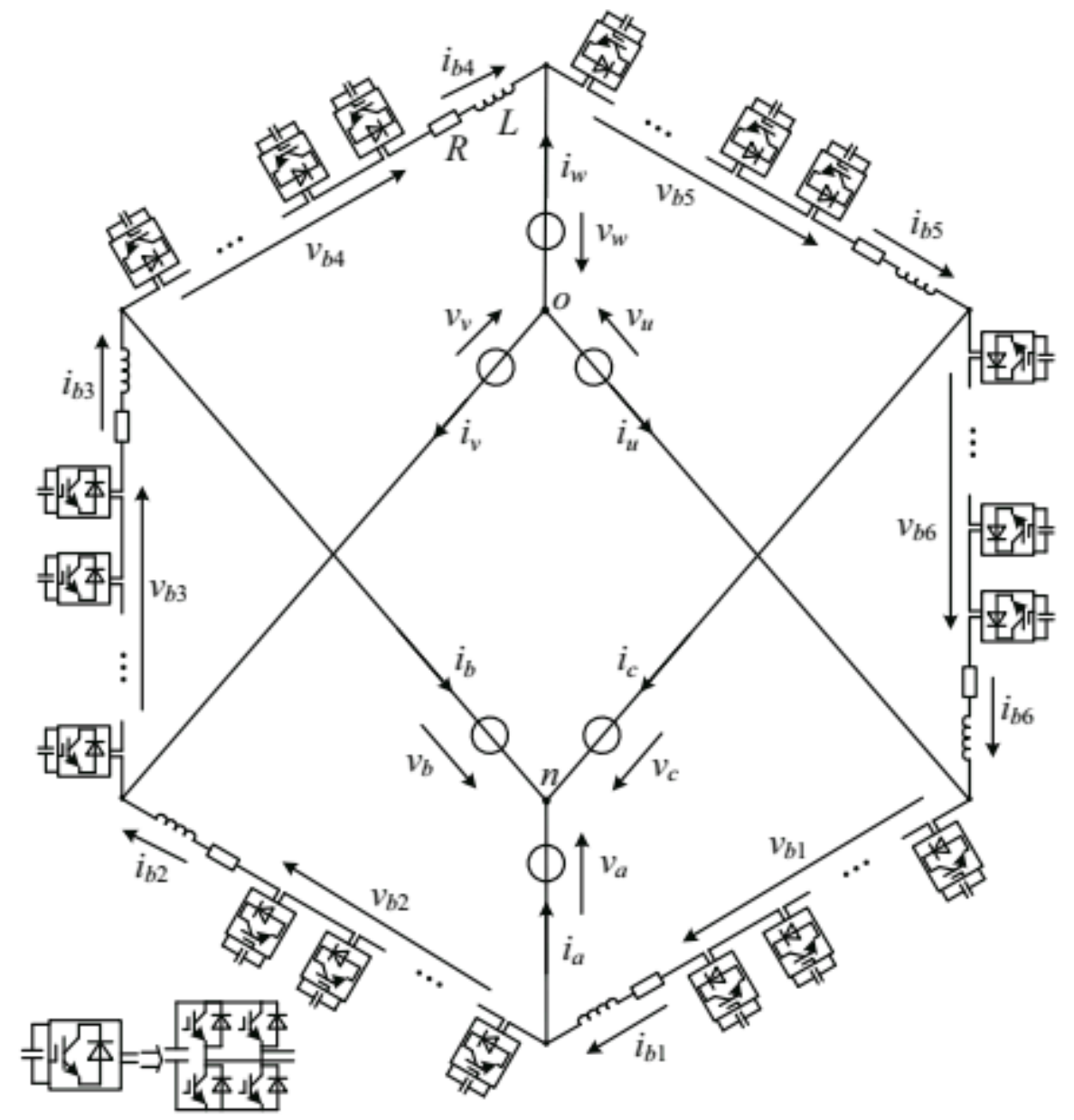

Figure 3. The hexverter converter.

This section also gives the state equations of hexverter, which derives conclusions regarding the reactive power constraints that need to be strictly satisfied in order to maintain system stability, and proposes the concept of transferring power between arms.

As shown above, each leg of the hexverter has a branch equivalent resistance, a branch-controlled series inductor, and an ideal voltage source. The input-side voltages and the currents of the system are $V_{u}, V_{v}, V_{w}, i_{u}, i_{v}, i_{w}$, respectively, and the output-side voltages and currents of the system are $V_{a}, V_{b}, V_{c}, i_{a}, i_{b}, i_{c}$, respectively. If the input and output system voltages are set at the neutral points, $V_{N O}=V_{s t}$, there would be a circulation of zero-sequence current $i_{c i r}$ in six branches. Suppose that the three-phase three-wire system has no electrical connection between the input-output systems at the neutral point, i.e., $i_{u}, i_{v}, i_{w}=0$, and $i_{a}, i_{b}, i_{c}=0$. Using the equal power transformation matrix, the $\alpha \beta o$ coordinate forms of the voltages and currents are obtained, as listed in Equations (1)-(12).

$$
\begin{gathered}
V_{s \alpha}=R i_{b \alpha 1}+L \frac{d i_{b \alpha 1}}{d t}+V_{b \alpha 1}+V_{l \alpha} \\
V_{s \beta}=R i_{b \beta 1}+L \frac{d i_{b \beta 1}}{d t}+V_{b \beta 1}+V_{l \beta} \\
V_{s o}=R i_{b o 1}+L \frac{d i_{b o 1}}{d t}+V_{b o 1}+V_{l o}+\sqrt{3} V_{N O} \\
V_{l \alpha}=R i_{b \alpha 2}+L \frac{d i_{b \alpha 2}}{d t}+V_{b \alpha 2}-\frac{1}{2} V_{s \alpha}+\frac{\sqrt{3}}{2} V_{s \beta}
\end{gathered}
$$




$$
\begin{gathered}
V_{l \beta}=R i_{b \beta 2}+L \frac{d i_{b \beta 2}}{d t}+V_{b \beta 2}-\frac{\sqrt{3}}{2} V_{s \alpha}-\frac{1}{2} V_{s \beta} \\
V_{l o}=R i_{b o 2}+L \frac{d i_{b o 2}}{d t}+V_{b o 2}+V_{s o}-\sqrt{3} V_{N O} \\
i_{b \alpha 1}=-\frac{1}{2} i_{b \alpha 2}-\frac{\sqrt{3}}{2} i_{b \beta 2}+i_{s \alpha} \\
i_{b \beta 1}=\frac{\sqrt{3}}{2} i_{b o 2}-\frac{1}{2} i_{b \beta 2}+i_{s \beta} \\
i_{b o 1}=i_{b o 2}+i_{s o} \\
i_{b \alpha 2}=i_{b \alpha 1}-i_{l \alpha} \\
i_{b \beta 2}=i_{b \beta 1}-i_{l \beta} \\
i_{b o 2}=i_{b o 1}-i_{l o}
\end{gathered}
$$

With respect to the fundamental outlines of the topology, it is necessary to change the coordinate framework to a $d_{q}$ reference outline in order to guarantee the level of flexibility. The $d_{q}$ reference frame controllers, with a quick internal current circle and an external loop, control the active and reactive power or the voltage magnitude. Therefore, after expanding, we obtain Equations (13)-(18).

$$
\begin{aligned}
& V_{b \alpha 1}=V_{s \alpha}-R\left(\frac{1}{2} i_{s \alpha}-\frac{1}{2 \sqrt{3}} i_{s \beta}\right)-L \frac{d}{d t}\left(\frac{1}{2} i_{s \alpha}-\frac{1}{2 \sqrt{3}} i_{s \beta}\right) \\
& \underbrace{-R\left(\frac{1}{2} i_{l \alpha}+\frac{1}{2 \sqrt{3}} i_{l \beta}\right)-L \frac{d}{d t}\left(\frac{1}{2} i_{l \alpha}+\frac{1}{2 \sqrt{3}} i_{l \beta}\right)-V_{l \alpha}}_{l} \\
& V_{b \beta 1}=\underbrace{}_{V_{s \beta}-R\left(\frac{1}{2 \sqrt{3}} i_{s \alpha}+\frac{1}{2} i_{s \beta}\right)-L \frac{d}{d t}\left(\frac{1}{2 \sqrt{3}} i_{s \alpha}+\frac{1}{2} i_{s \beta}\right)} \\
& \underbrace{-R\left(-\frac{1}{2 \sqrt{3}} i_{l \alpha}+\frac{1}{2} i_{l \beta}\right)-L \frac{d}{d t}\left(-\frac{1}{2 \sqrt{3}} i_{l \alpha}+\frac{1}{2} i_{l \beta}\right)-V_{l \beta}}_{l} \\
& V_{b o 1}=V_{s o}-R i_{b o 1}-L \frac{d i_{b o 1}}{d t}-V_{l o}-\sqrt{3} V_{N O} \\
& V_{b \alpha 2}=\underbrace{V)}_{V_{l \alpha}-R\left(-\frac{1}{2} i_{l \alpha}+\frac{1}{2 \sqrt{3}} i_{l \beta}\right)-L \frac{d}{d t}\left(-\frac{1}{2} i_{l \alpha}+\frac{1}{2 \sqrt{3}} i_{l \beta}\right)} \\
& \underbrace{-R\left(\frac{1}{2} i_{s \alpha}-\frac{1}{2 \sqrt{3}} i_{s \beta}\right)-L \frac{d}{d t}\left(\frac{1}{2} i_{s \alpha}-\frac{1}{2 \sqrt{3}} i_{s \beta}\right)+\frac{1}{2} V_{s \alpha}-\frac{\sqrt{3}}{2} V_{s \beta}}_{s} \\
& V_{b \beta 2}=\underbrace{V_{l \beta}-R\left(-\frac{1}{2 \sqrt{3}} i_{l \alpha}-\frac{1}{2} i_{l \beta}\right)-L \frac{d}{d t}\left(-\frac{1}{2 \sqrt{3}} i_{l \alpha}-\frac{1}{2} i_{l \beta}\right)}_{l} \\
& \underbrace{-R\left(\frac{1}{2 \sqrt{3}} i_{s \alpha}+\frac{1}{2} i_{s \beta}\right)-L \frac{d}{d t}\left(\frac{1}{2 \sqrt{3}} i_{s \alpha}+\frac{1}{2} i_{s \beta}\right)+\frac{\sqrt{3}}{2} V_{s \alpha}+\frac{1}{2} V_{s \beta}}_{s}
\end{aligned}
$$




$$
V_{b o 2}=V_{l o}-R i_{b o 2}-L \frac{d i_{b o 2}}{d t}-V_{s o}+\sqrt{3} V_{N O}
$$

The bridge arm voltages $V_{b \alpha 1}, V_{b \beta 1}$ and $V_{b \alpha 2}, V_{b \beta 2}$ in both the input and yield contains two frequency segments that are not viewed as a zero-sequence segments.

Using these equations, a control system can be built. It can be adjusted to achieve active and reactive current closed-loop control using a PI controller. The $V_{b s d 2^{\prime}}^{\prime} V_{b s q 2}^{\prime}, V_{b l d 1}^{\prime}, V_{b l q 1}^{\prime}, V_{b l d 2^{\prime}}^{\prime} V_{b l q 2}^{\prime}$ and $V_{b o 1}^{\prime}, V_{b o 2}^{\prime}$ are obtained from the current loop of the PI controller that controls the principle. The hexverter contains three control schemes for operation, i.e., an inner loop for current control, an outer loop for voltage control, and a circulating current control loop, as shown in Figures 4-6. All of these control loops can be easily derived from Equations (13)-(18).
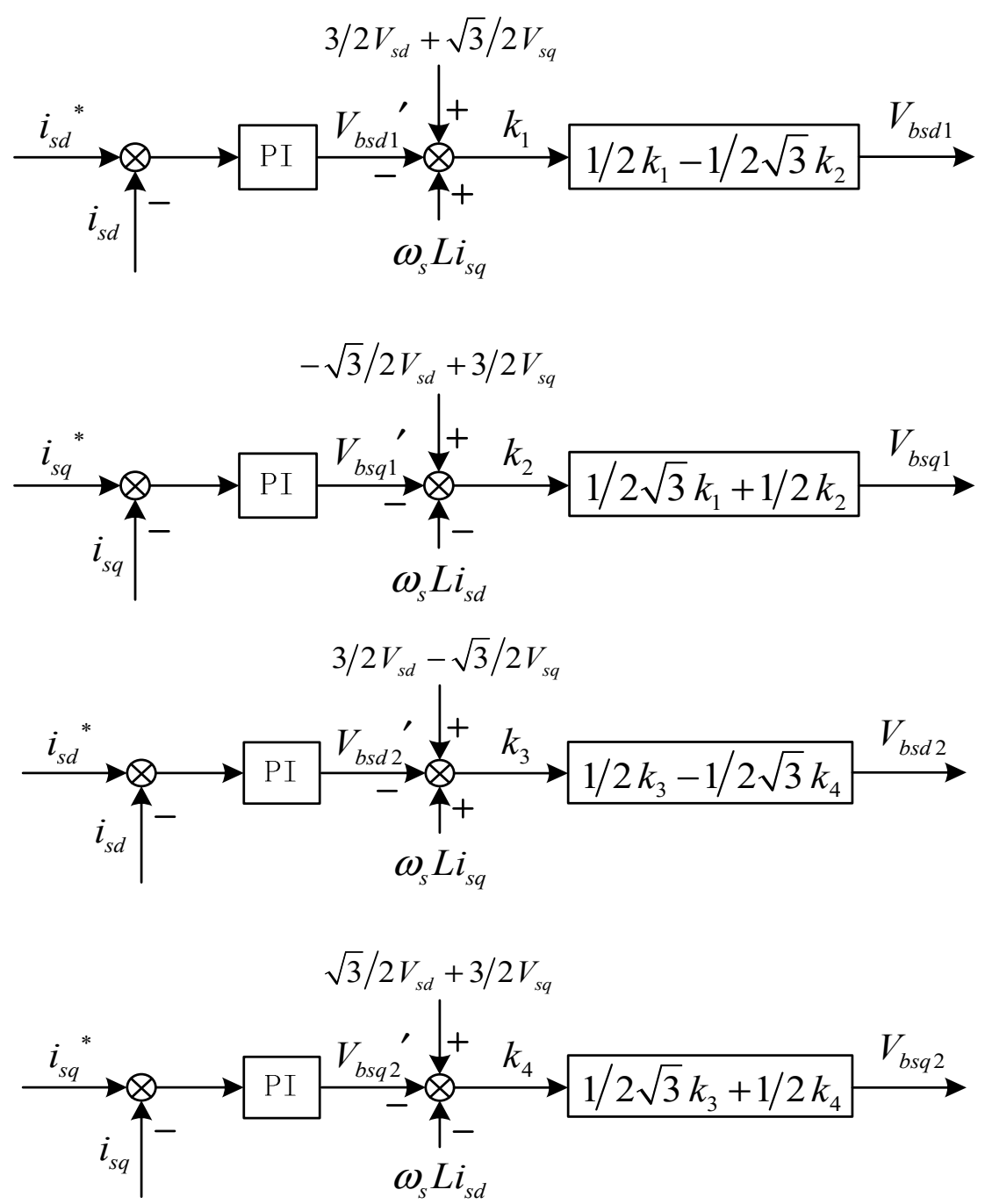

Figure 4. Control loop of PI controller for system 1. 

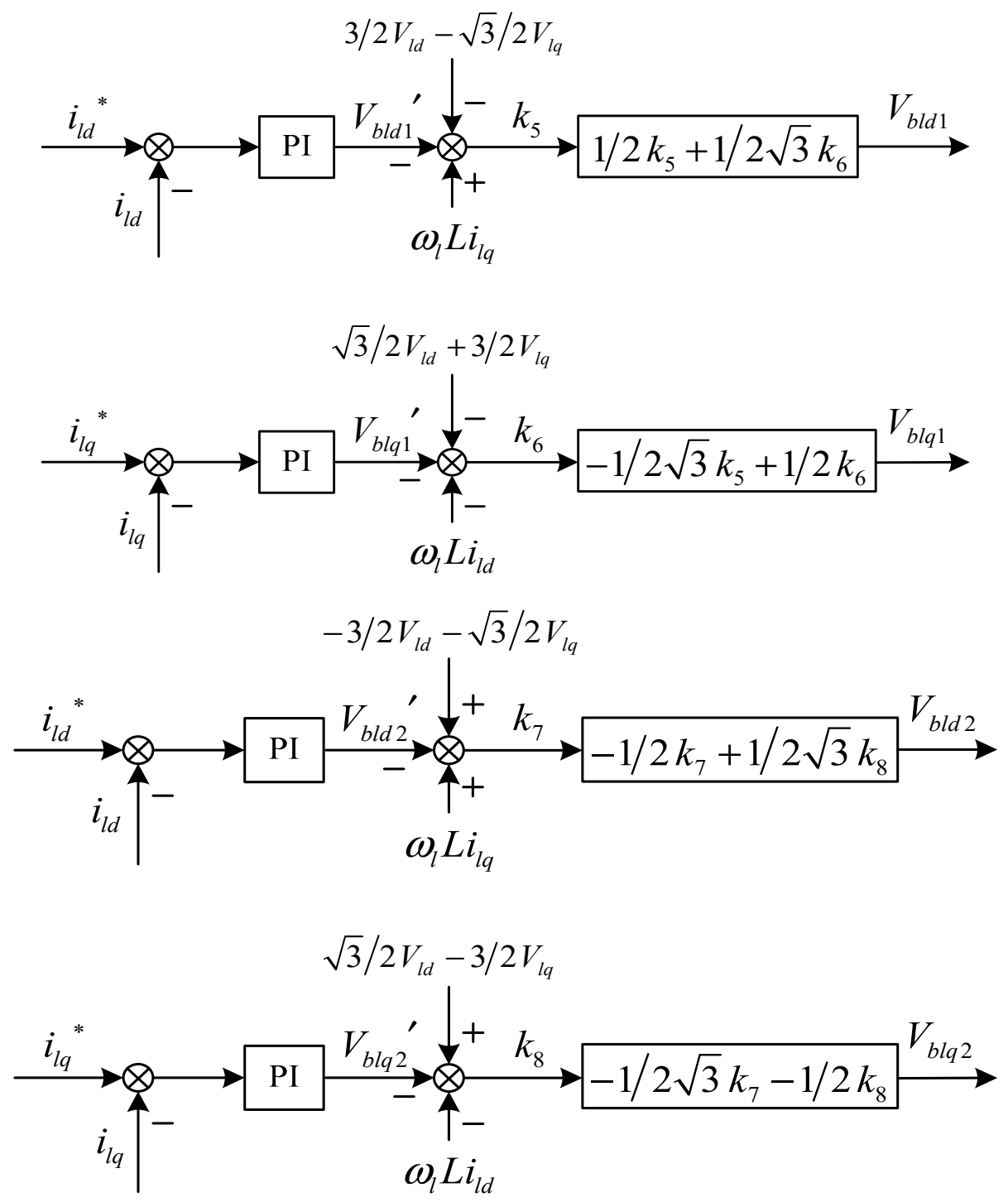

Figure 5. Control loop of PI controller for system 2.
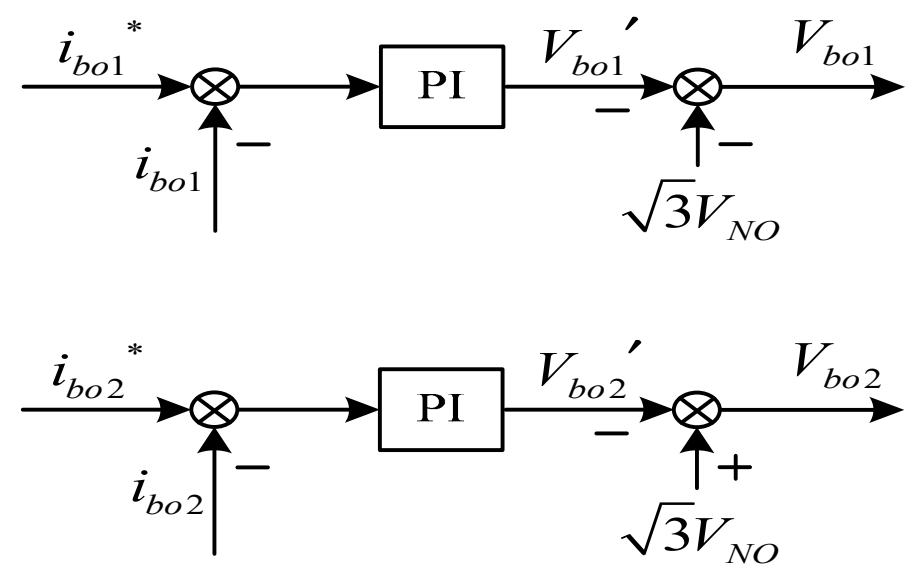

Figure 6. Current control loop of PI controller for zero sequence.

The inner loop current controller receives current commands produced by the outer loop voltage control and generates the voltage commands for all of the branch submodules (SMs). The simulation model applies phase-shift pulse-width modulation (PS-PWM) to communicate the voltage commands. 
Each of the voltage commands is compared with its corresponding triangular carrier waveform, generating gate signals.

The outer loop voltage control methods of the hexverter in an integrated wind power system are similar to those of the converter station in an HVDC system. The detailed derivations of these are not presented here, since such methods have already been widely used in various devices and can be easily found in other references.

When offshore wind power is integrated into an industrial grid via LFAC, it can be considered to be a negative load with indeterminate frequency and voltage connected to the LFAC or fractional frequency (FF) side of the hexverter. The hexverter is used to provide busbar voltage and frequency support. It is difficult to determine the active and reactive power at the FF side of the hexverter, because the output active power of an offshore wind farm fluctuates with wind speed, and the reactive power is influenced by the length of the transmission cable. Hence, the outer loop voltage control method (used for grid-connected mode) no longer works for the hexverter in the passive mode. Outer loop voltage control in the passive mode uses a filter capacitor.

As both neutral points of the systems are isolated, there are no zero-sequence currents. Therefore, the phase currents of both systems can only be expressed by their corresponding values. In addition to system currents, the purported "circulating current" can be defined as an inner current that flows through all branches of the hexagonal converter, but does not affect the system currents. Connection of the circulating current and the branch current of the arms for the three-phase three-wire network can be defined when there is no electrical association between the yield of the framework with the unbiased point, $i_{u}, i_{v}, i_{w}=0, i_{a}, i_{b}, i_{c}=0$ and $i_{b o 1}=i_{b o 2}=i_{b o}$. Therefore, zero-sequence current can be defined as in Equation (19),

$$
i_{c i r}=\frac{\sum_{i=1}^{6} i_{b i}}{6}=\frac{i_{b o}}{\sqrt{3}}
$$

and for different operating conditions as expressed by Equation (20).

$$
\begin{gathered}
Q_{1}+Q_{2} \neq 0 \\
\frac{Q_{1}+Q_{2}}{6 \sqrt{3}}=V_{N O} i_{c i r}
\end{gathered}
$$

where $V_{N O}$ is the voltage between the neutral point of input system and output system, $i_{c i r}$ is the zero-sequence circulating current of six arms, and Q1 and Q2 are the hexverter reactive power from $\mathrm{AC}$ systems 1 and 2 respectively. Considering the voltage regulation and reactive power demand, the equation $\mathrm{Q} 1+\mathrm{Q} 2 \neq 0$ is always satisfied, making the circulating current $i_{\text {cir }}$ non-zero. It is obvious from research on power electronics converters that the circulating current has a significant impact on the overall power rating and efficiency of the converter because of the huge number of semiconductor devices. Moreover, these semiconductor devices collectively result in a cascaded circulating current, so this novel control strategy optimizes this circulating current to the minimum value. The presence of circulating current increases the switching loss, and therefore reduces the efficiency of the system. In addition to this strict constraint, the reactive power also increases the difficulty of the control strategy.

From the smallest and most productive point of view, zero sequence current must be minimized in order to meet the essential conditions of the H-MMC converter. Equations (21)-(23) express the relation of zero-sequence current optimization, which can also be visualized from Figure 7, which shows the dependence of circulating current on constant values and system voltages. Important parameters of hexverter are shown in Table 1.

$$
\begin{gathered}
V_{N O}=\frac{1}{2 \sqrt{3}}\left(V_{b o 2}-V_{b o 1}\right) i_{c i r}=\frac{i_{b o}}{\sqrt{3}} \\
i_{b o}=-\frac{1}{2 R}\left(V_{b o 1}+V_{b o 2}\right)
\end{gathered}
$$




$$
i_{c i r}=\frac{i_{b o}}{\sqrt{3}}=-\frac{1}{2 \sqrt{3} R}\left(V_{b o 1}+V_{b o 2}\right)
$$

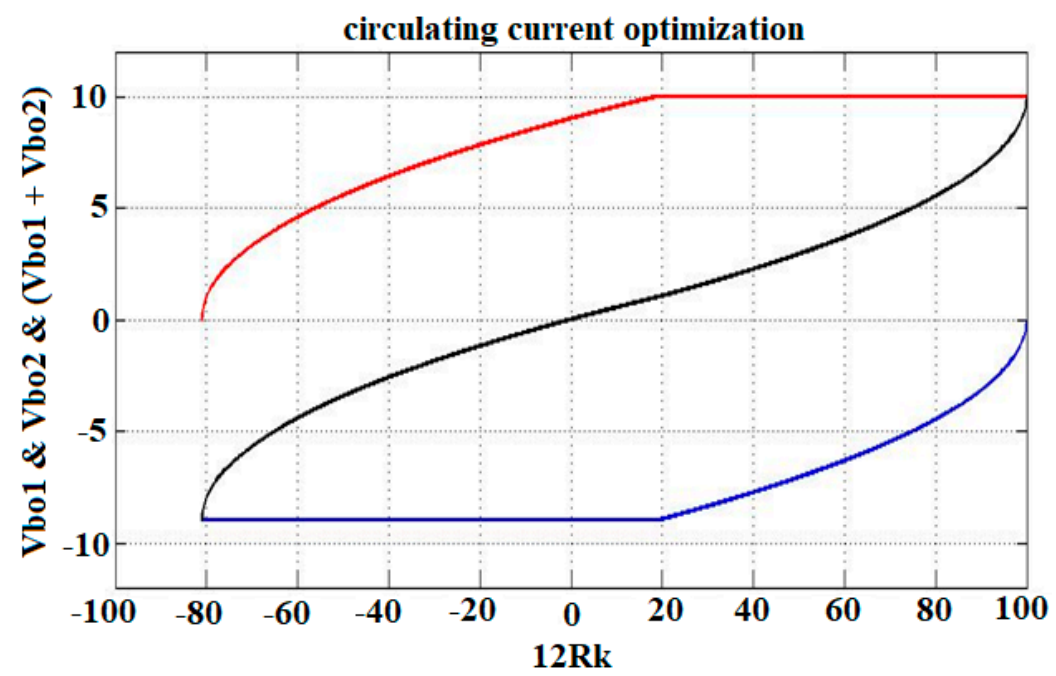

Figure 7. Zero-sequence current optimization.

Table 1. Hexverter Parameters Used in Simulation.

\begin{tabular}{cccc}
\hline Parameters & Value & Parameters & Value \\
\hline $\mathrm{R}$ & $0 \Omega$ & $\mathrm{P}_{\mathrm{tr}}$ & $10 \times 10^{6} \mathrm{~W}$ \\
$\mathrm{~L}$ & $10 \times 10^{-3} \mathrm{H}$ & $\mathrm{V}_{\mathrm{s} \_ \text {Ref }}$ & $10 \times 10^{3} \mathrm{~V}$ \\
$\mathrm{C}_{\mathrm{dc}}$ & $20,000 \times 10^{-6} \mathrm{~F}$ & $\mathrm{~V}_{\mathrm{m}-\text { ref }}$ & $10 \times 10^{3} \mathrm{~V}$ \\
$\mathrm{~V}_{\mathrm{dc} 0}$ & $2.0 \times 10^{3} \mathrm{~V}$ & $\mathrm{~T}_{\mathrm{c}}$ & $1.2 \times 10^{-3} \mathrm{~s}$ \\
$\mathrm{~V}_{\mathrm{dc}-\mathrm{ref}}$ & $18 \times 10^{3} \mathrm{~V}$ & $\mathrm{~N}$ & 6 \\
\hline
\end{tabular}

Figure 2 visualizes the hexverter block as a frequency converter, and it contains a further four blocks that contain second-order low pass filters, a converter control system based on the above control strategy and equations, a degree to radian converter, and a PWM pulse generator according to the six arms of the hexverter, which further contains the semiconductor devices connected to each arm of the converter.

The control system of the frequency converter is shown in Figure 8. It is designed to minimize the zero-sequence current, and has several components working together to give this work a degree of novelty, as it has not been addressed before in this way, especially for circulating current. The control system of the hexverter also regulates the AC and DC voltages, and ensures that the AC and DC voltage behavior correctly overrides the set value. The active power regulation, which has already been discussed in the hexverter control section, leads to perfect control equations, the abc to dq reference frame converter, the source dq current regulator, the load dq current regulator, and the hexverter zero axis current regulator. 

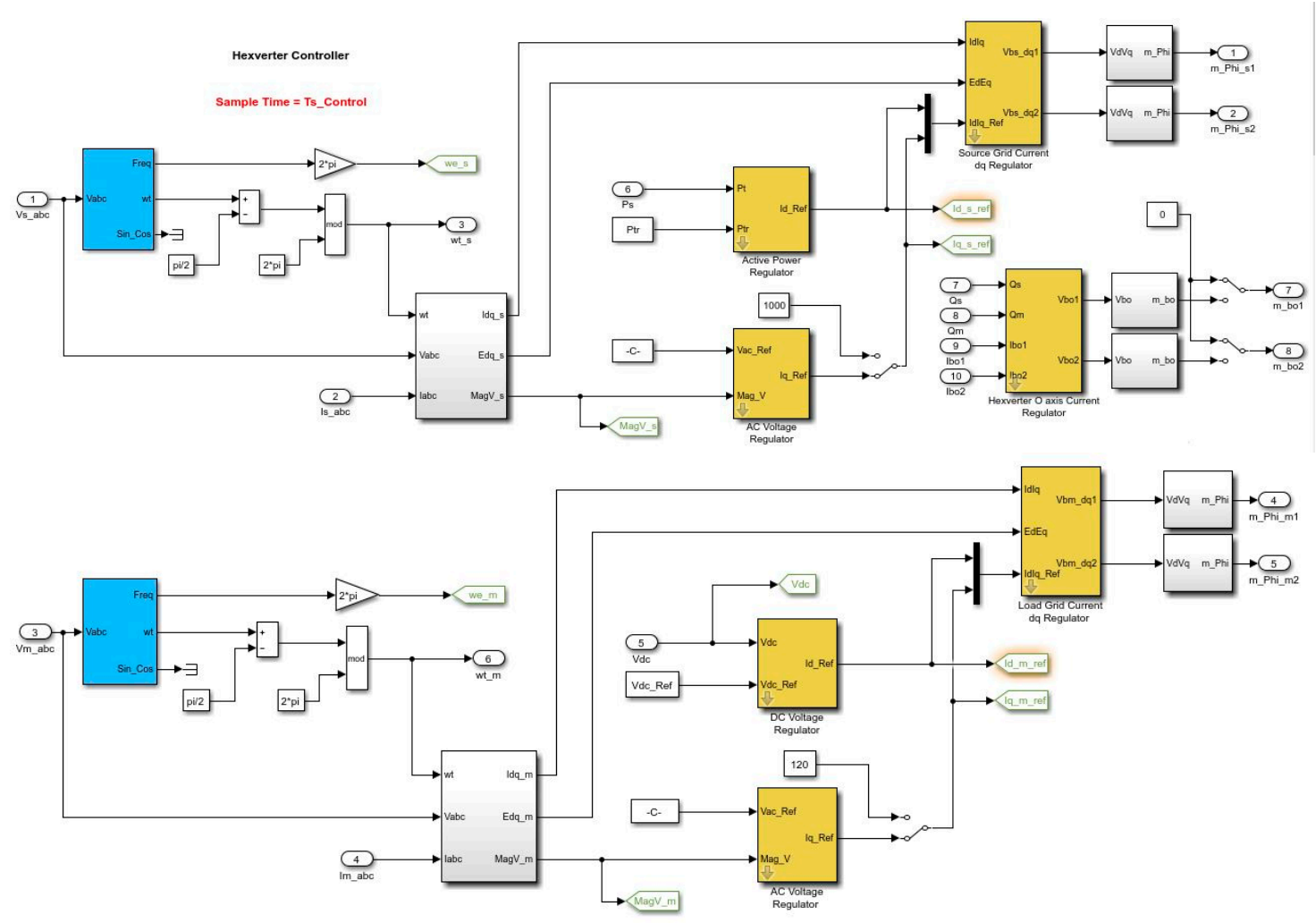

Figure 8. Control system for hexverter.

\subsection{Motors, VSD Modeling and Its Control System}

For subsea T\&D system, motors are necessarily required to drive the pumps and compressors for subsea processing. Pumping oil from the seabed requires a very heavy-duty motor that can support pumps.

The VSD + Motor block in Figure 2 contains a vector control-based VSD to drive a 5 MW subsea induction motor and a 5 MW RL general-purpose load (connected with the undersea distribution transformer). After an intensive study of the literature, the parameters of the subsea motors, transformer, and cables were carefully chosen [14].

The vector control is also known as Field Oriented Control (FOC). It is a Variable Frequency Drive (VFD) control technique in which the stator currents of the three-phase electric motor are identified as two orthogonal components. These two orthogonal components can be visualized using a vector. These components define the magnetic flux and the torque of the motor. The control system of the drive computes the respective current component references from the flux and torque. The proportional-integral (PI) controllers are typically used to maintain the measured current components at their reference values. Pulse width modulation of the variable frequency drive (VFD) expresses the transistor switching according to the stator voltage references that are output by the PI current controllers [14]. It is expected that FOC will universally displace single-variable scalar volts-per-Hertz (V/f) control because of the increasing computational power of microprocessors.

The Simulink model of the VSD is shown in Figure 9. This block has a diode rectifier working on a harmonics eliminator technique with which a zigzag transformer connection is employed to give the motor better isolation in the case of harmonics occurrence. The wind turbine farm consists of a synchronous generator and the $5 \mathrm{MW}$ induction motor on the distribution side, which causes harmonics in real-time. To simulate this situation, artificial harmonics are injected into the system to make it as real-time as possible. To overcome these real-time contingencies, the control system of the system is designed in such a way that these problems can be handled. Only harmonics and wind speed are taken as disturbances, and these are handled by the designed control system. 


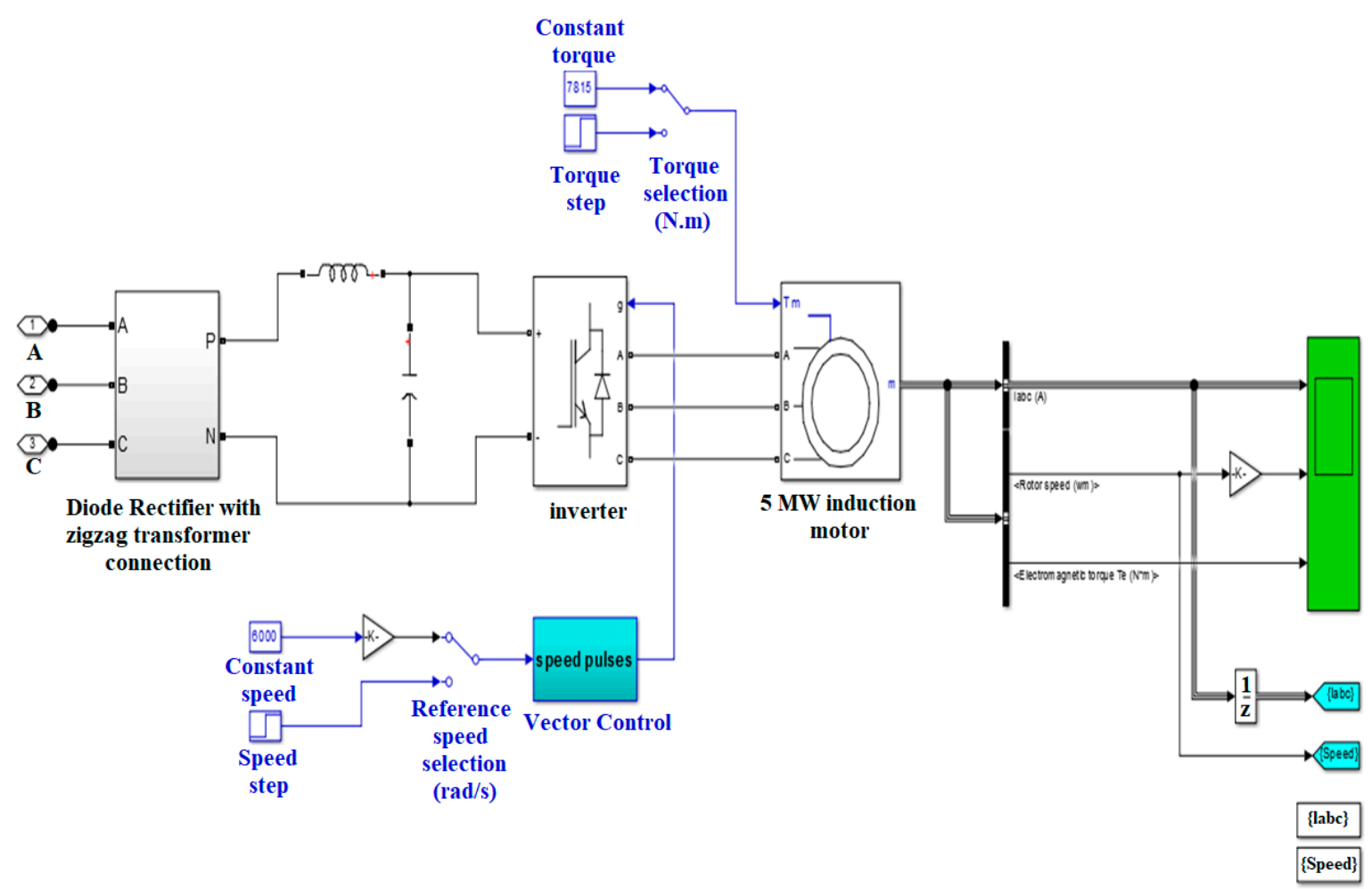

Figure 9. SIMULINK model of VSD using the vector control method.

The parameters of the induction motor were selected to meet real-life requirements. As this motor is intended for subsea use, this particular model is not available. The resistance and inductance of the rotor and the stator were selected carefully, because the motor has to operate at LFAC. It will have different resistance and mutual induction parameters compared to a motor that operates at $50 \mathrm{~Hz}$.

The parameters of the induction motor used in our work are listed in Table 2.

Table 2. Induction motor parameters.

\begin{tabular}{cc}
\hline Parameters & Value \\
\hline Pmotor & $5 \mathrm{MW}$ \\
P.F & 0.8 \\
Line Voltage & $6.6 \mathrm{KV}$ \\
Speed & $6000 \mathrm{rpm}$ \\
No of Poles & 2 \\
\hline
\end{tabular}

The variable-speed drive (VSD) employed in our system is based on vector control, which works on the basis of a speed controller, two-way conversion of abc to dq reference frame and vice versa, flux and angle calculations, Iq and Id current calculators, and its regulator. Constant speed is provided to the controller for reference, and our control system works perfectly with respect to achieving reference speed for maintaining the torque required by the motor within seconds, as is discussed in detail in the Results section.

\subsection{Offshore Wind Farm}

The following figure depicts the Simulink block diagram of the integrated wind farm. This farm provides $20 \mathrm{MW}$ of power to the system using a permanent magnet synchronous generator at $16 \mathrm{~Hz}$ frequency. This wind farm is located offshore, and is connected with the subsea T\&D system by $5 \mathrm{~km}$ subsea transmission lines, as shown in Figure 2. A lot of research work has been done on the integration 
of offshore wind farms [15]. Figure 10 shows the Simulink model of the wind farm, which is integrated with the subsea T\&D system through LFAC transmission technology.
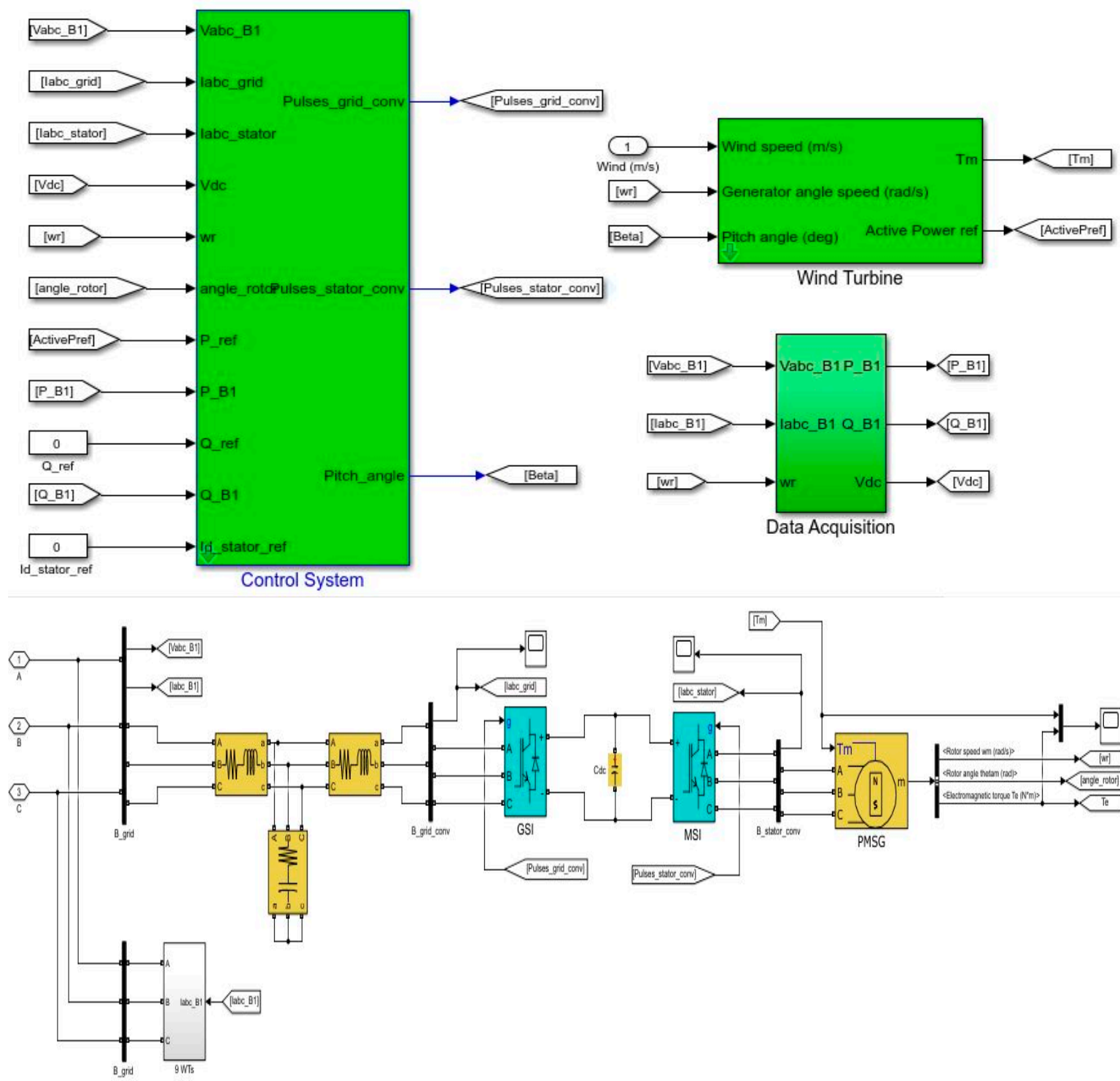

Figure 10. PMSG-based $20 \mathrm{MW}$ wind farm SIMULINK model.

The Simulink model of the wind farm contains some major components, including a grid-side inverter (GSI), a machine-side inverter (MSI), and wind turbines. The control system block has a set of low-pass filters with a cutoff frequency of $4000 \mathrm{~Hz}$ and damping factor zeta of $70 \%$.

Control of the grid-side inverter (GSI) has an abc to dq reference frame converter and a Vdc regulator. As the length of the transmission line affects the reactive power, which further calls the stability of the system into question, a current and reactive power regulator is employed here. The PI controller is used, employing the reference values of Vdc, Iq and Id. The machine-side inverter (MSI) requires an angle calculation, and based on that calculation, the dq reference frame is converted to abc again. A discrete PI controller-based current and power regulator is employed in MSI control. The designed controller is then fed via the space vector PWM module to the inverter of both sides, i.e., GSI and MSI.

The data acquisition block just measures the active and reactive powers generated by the farm and sends the signal to the display block in order to observe its behavior. The wind turbine block 
contains the essential data of 9 wind turbines, i.e., wind speed, generator angle speed, and pitch angle, as well as its calculation.

\subsection{Subsea Transmission Line}

The purpose of a transmission system is to transfer power from the power source (on the platform) to the electrical equipment on the seabed. The subsea pumps and compressors are one of the main power consumers among such equipment. Generally, there are numerous requirements that specify the amount of voltage to be supplied to the terminals of the motors in order to drive the pumps and compressors. Subsequently, the purpose of the supply system is to supply a voltage equivalent to the nominal terminal voltage increased by the amount of voltage drop in the transmission system.

The choice of a suitable cable model can be determined by its length. Lengths within a range of 5-50 km are investigated in our research work. The simplest short cable model is not considered, because of its charging capacities are distributed along the cable. With increasing cable length, these capacitances become significantly larger, and therefore cannot be neglected. For the above-mentioned reasons, the medium line model/Pi Model shown in Figure 11 is selected for software simulation and the calculation of equivalent impedance. The selected model assumes that line charging current and shunt capacitance makes it possible to obtain the necessary level of accuracy, particularly for subsea cables and their application [16].

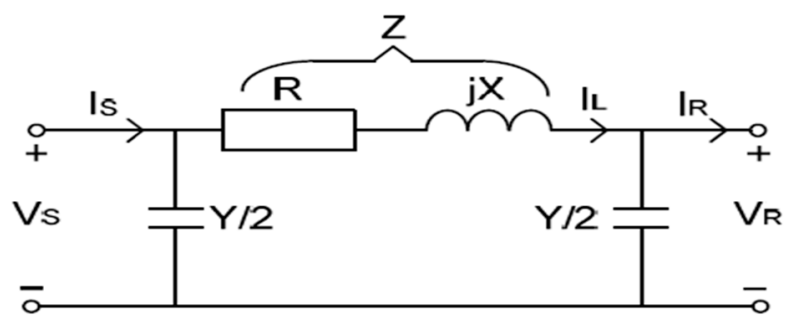

Figure 11. Medium-length line model.

where,

- VS and VR are the voltages on the sending and receiving end,

- IS and IR are the currents on the sending and receiving end,

- IL is current in the series impedance,

- $\mathrm{R}, \mathrm{X}$ and $\mathrm{Z}$ are resistance, reactance and total impedance of the cable,

- $\quad \mathrm{Y}$ is the admittance.

The medium length line model is described by Equations (24) and (25) given below:

$$
\begin{gathered}
V_{S}=1+\frac{z \times y}{2} \times V_{R}+z \times I_{R} \\
I_{S}=1+\frac{z \times y}{4} \times V_{R}+\left(1+\frac{z \times y}{2}\right) \times I_{R}
\end{gathered}
$$

To choose the proper size of the cable, the current $I_{\text {motor }}$ required for the subsea motor is calculated by Equation (26):

$$
I_{\text {motor }}=\frac{P_{\text {motor }}}{\sqrt{3} \times U l_{\text {motor }} \times \cos \alpha}
$$

- $P_{\text {motor }}$ is the motor active power,

- $U_{l l}$ is line-to-line terminal voltage,

- $\cos \alpha$ is the power factor 
The final decision to increase the cable cross-sectional area can be made after carrying out a comprehensive technical and economic analysis. As for as the transmission distance is concerned, it depends on the frequency as can be observed from Equations (27) to (29) given below:

$$
\begin{gathered}
V_{R E}=\frac{V_{S E}}{\cos (d \omega \sqrt{L C})} \times \frac{1}{f} \\
d_{\max } V=\operatorname{acos}\left(\frac{1}{k}\right) \frac{1}{2 \pi \sqrt{L C}} \frac{1}{f} \\
d_{\max } V=\frac{2}{2 \pi \times C V_{S E}} \frac{1}{f}
\end{gathered}
$$

In both of the expressions shown above in Equations (28) and (29), we can see that the transmission distance is inversely proportional to the frequency; therefore, for the given transmission voltage, the maximum transmission distance of a power cable will increase as the transmission frequency decreases. However, the size of the passive components such as the transformer will also increase. A transformer operating at $16 \mathrm{~Hz}$ will be three times bigger and heavier than a $50 \mathrm{~Hz}$ transformer. However, the losses will be $50 \%$ less in the low-frequency transformer. Some other factors can also affect cable performance. One of them is a line-charging current, which has a directly proportional relationship with the transmission frequency and the line capacitance. The greater the frequency, the greater the charging current, which ultimately leads to greater losses. The lower the frequency, the lower the charging current, and the longer the distance will be with respect to more power and more current. Equation (30) represents the cable current carrying capability.

$$
I_{C}=V_{S E} \times \omega C
$$

For subsea transmission, the currently available subsea cables "245-KV XPLE cable" can be considered to transmit $600 \mathrm{MW}$ of power up to $400 \mathrm{~km}$ if low frequency (such as $16 \mathrm{~Hz}$ ) is used, but if we use a frequency of 50 or $60 \mathrm{~Hz}$, the distance will be reduced to $100 \mathrm{~km}$ because of the charging current, which is dependent on frequency. Low frequency also increases the stability of the voltage, by giving the same amount of reactive power transmission, as shown in Equation (31),

$$
\Delta v \%=\frac{Q_{X}}{V^{2}} \times 100
$$

where $\Delta v$ is the voltage drop over the line, $\mathrm{V}$ is the nominal voltage, and $\mathrm{Q}$ is the reactive power flow of the cable. As impedance decreases in the LFAC, the voltage drop through the cable also decreases proportionally, as expressed by Equation (32).

$$
X=2 \pi f L
$$

Active power transmission also improves with the LFAC transmission system. Equation (33) shows that at a given transmission angle, if the frequency goes up, $\mathrm{X}$ will go down, and power will ultimately go up

$$
p=\frac{V_{S} V_{R}}{X} \times \sin \delta
$$

Table 3 presents a comparison of the parameters of two different types of cables, showing how $16 \mathrm{~Hz}$ vs. $50 \mathrm{~Hz}$ transmission can affect the parameters of the submarine cable. 
Table 3. Cable parameter, $50 \mathrm{~Hz}$ vs. $16 \mathrm{~Hz}$.

\begin{tabular}{|c|c|c|c|c|}
\hline & \multicolumn{2}{|c|}{$3 \times 1200 \mathrm{~mm}^{2} \mathrm{Cu} / \mathrm{RM}$} & \multicolumn{2}{|c|}{$3 \times 2000 \mathrm{~mm}^{2}$ AI RE } \\
\hline & $50 \mathrm{~Hz}$ & $16 \mathrm{~Hz}$ & $50 \mathrm{~Hz}$ & $16 \mathrm{~Hz}$ \\
\hline $\mathrm{R}(\Omega / \mathrm{km})$ & 0.0319 & 0.0204 & 0.0381 & 0.0222 \\
\hline $\mathrm{L}(\mathrm{mh} / \mathrm{km})$ & 0.373 & 0.373 & 0.354 & 0.354 \\
\hline$C(\mathrm{nf} / \mathrm{km})$ & 191 & 191 & 227 & 227 \\
\hline $\mathrm{X}(\mathrm{m} \Omega / \mathrm{km}$ & 117.2 & 39.1 & 111.2 & 37.1 \\
\hline$\omega \mathrm{C}(\mathrm{ms} / \mathrm{km})$ & 60.0 & 20 & 71.3 & 23.8 \\
\hline $\mathrm{G}(\mathrm{nS} / \mathrm{km})$ & 60 & 20 & 71 & 22 \\
\hline $\mathrm{I}_{\max }(\mathrm{KA})$ & 1.225 & 1.5 & 1.225 & 1.5 \\
\hline
\end{tabular}

\section{Performance and Discussion of Results}

In Figure 12, the output of the frequency converter, which converts the grid-side standard frequency into the $16 \mathrm{~Hz}$ frequency with $8.2 \mathrm{KV}$ and $835 \mathrm{~A}$ magnitude instead of $10 \mathrm{KV}$ is due to the losses of the semiconductor devices. The input and output voltage of the hexverter frequency converter are approximately $10 \mathrm{KV}$ and $8.2 \mathrm{KV}$ (before stepping up to $132 \mathrm{KV}$ ), respectively. The capacitors in the model are used to compensate for the losses; for this reason, we can consider our input and output voltage to be close to each other. After that, we step up the 10-132 KV level for the sake of transmission. The magnitude of the voltage and current after stepping up to $132 \mathrm{KV}$ can be seen from the different node connections. Importantly, another $16 \mathrm{~Hz}$ source is used for our system (at S16 node) in order to assist the original hexverter performance. We can see from the results of the active and reactive power of the hexverter that the active power is $10 \mathrm{MW}$ and shows good behavior, but the reactive power is very close to zero and has negligible fluctuations, as can be observed from Figure 13.

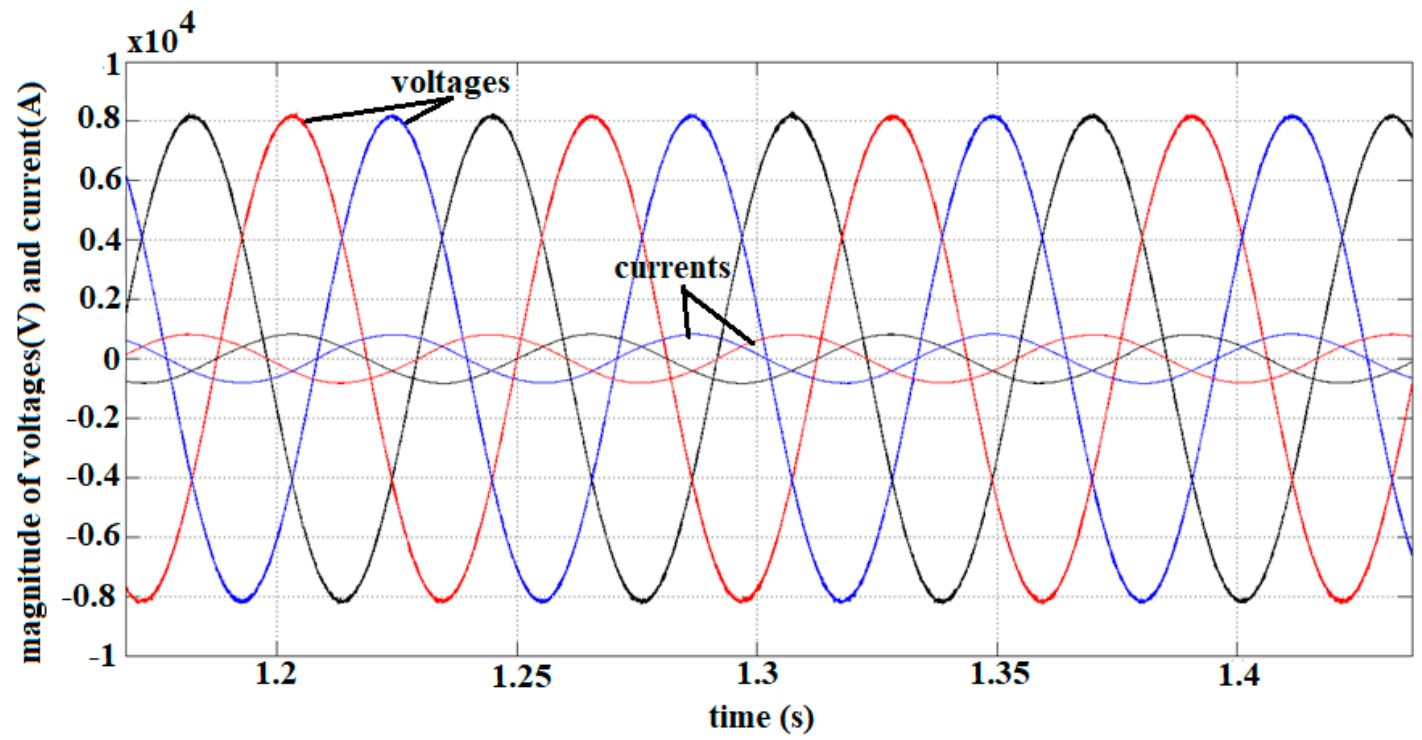

Figure 12. Hexverter's output voltage and current waveforms. 


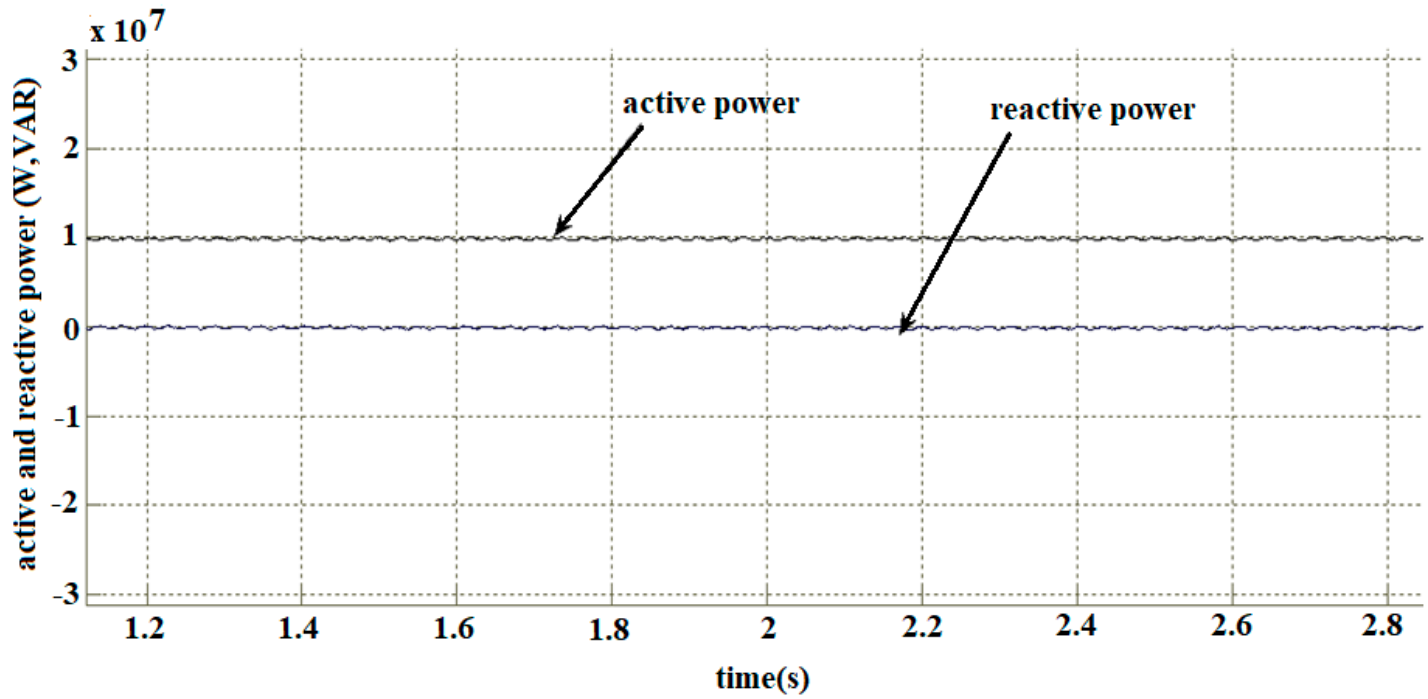

Figure 13. Active and reactive power waveforms of hexverter.

This might be due to the lack of a filter or maybe due to the high harmonics current from the load side because, at load, we are using such a high-power inductive load due to the nonlinear components in VSD. If we talk about the power tracking waveform, Figure 14 shows that the power is on the right track after the $0.1 \mathrm{~s}$, and will achieve steady state at $10 \mathrm{MW}$. Although we used a zigzag transformer to completely isolate the load, there are still some harmonics that cause fluctuations and dwindling in the behavior of the reactive power. Overall the phase-wise current and voltage behavior is healthy.

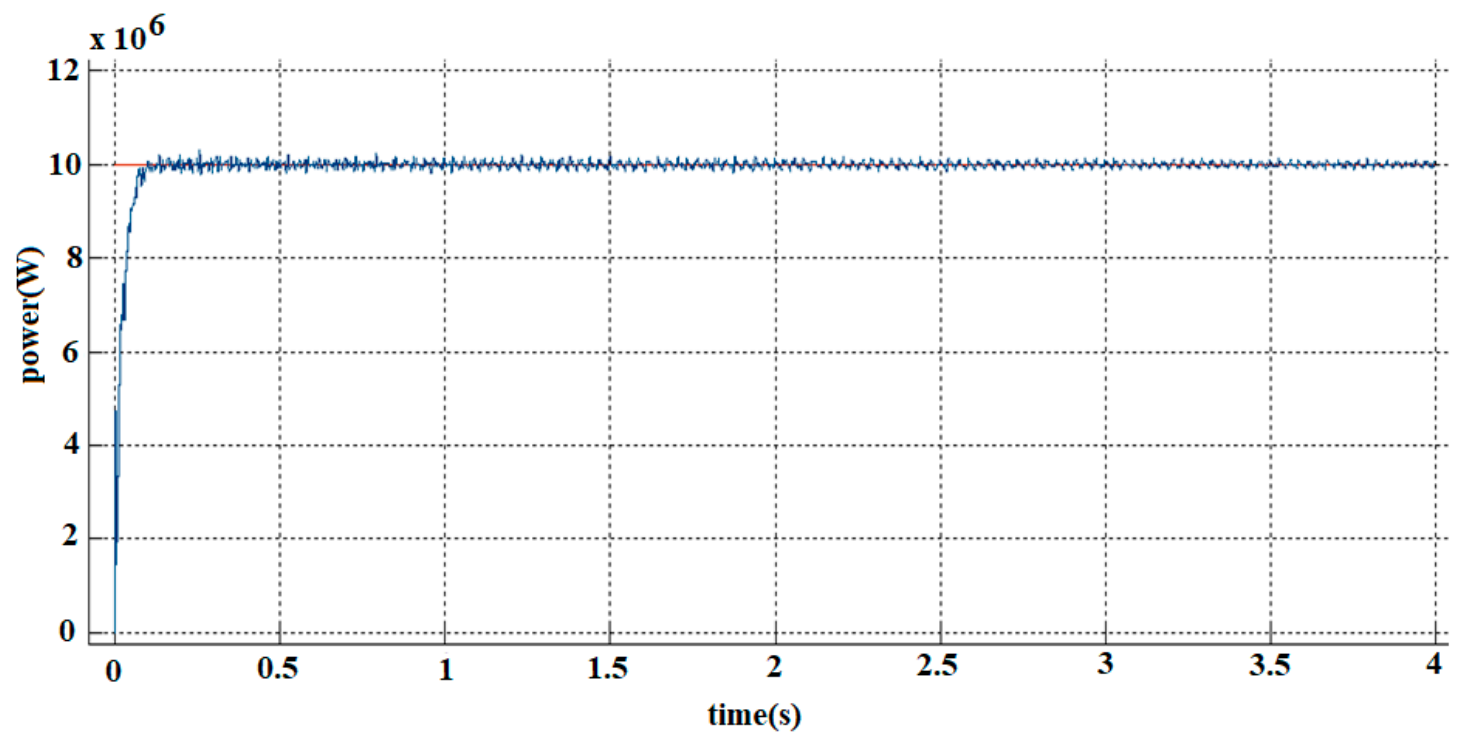

Figure 14. Hexverter active power tracking.

The other thing that can be affected by the stability of the DC voltage levels within the hexverter is the voltage balancing technique, which could be beneficial in controlling the long-time run fluctuation.

All of the control strategies and conversions have already been discussed in the previous sections. Based on these calculations, Figures 15-18 visualize the input and output-side ( $\mathrm{d}$ and $\mathrm{q}$ ) current tracking performances. As far as the $\mathrm{d}$ axis current is concerned, the waveform of the input and output are both set to the steady state after $0.75 \mathrm{~s}$. However, before $0.75 \mathrm{~s}$, the output-side (d axis) current shows some dynamic behavior. The $\mathrm{q}$ axis current is different with respect to input and output frames. From Figures 16 and 18, it can be seen that the output q axis current is close to zero, with good tracking, but in 
the case of the input side, it shows harmonics at a magnitude of almost $25 \mathrm{~A}$. Overall, the performance of the control system is very good, because the actual current tracks the reference value very quickly and without any overshoot.

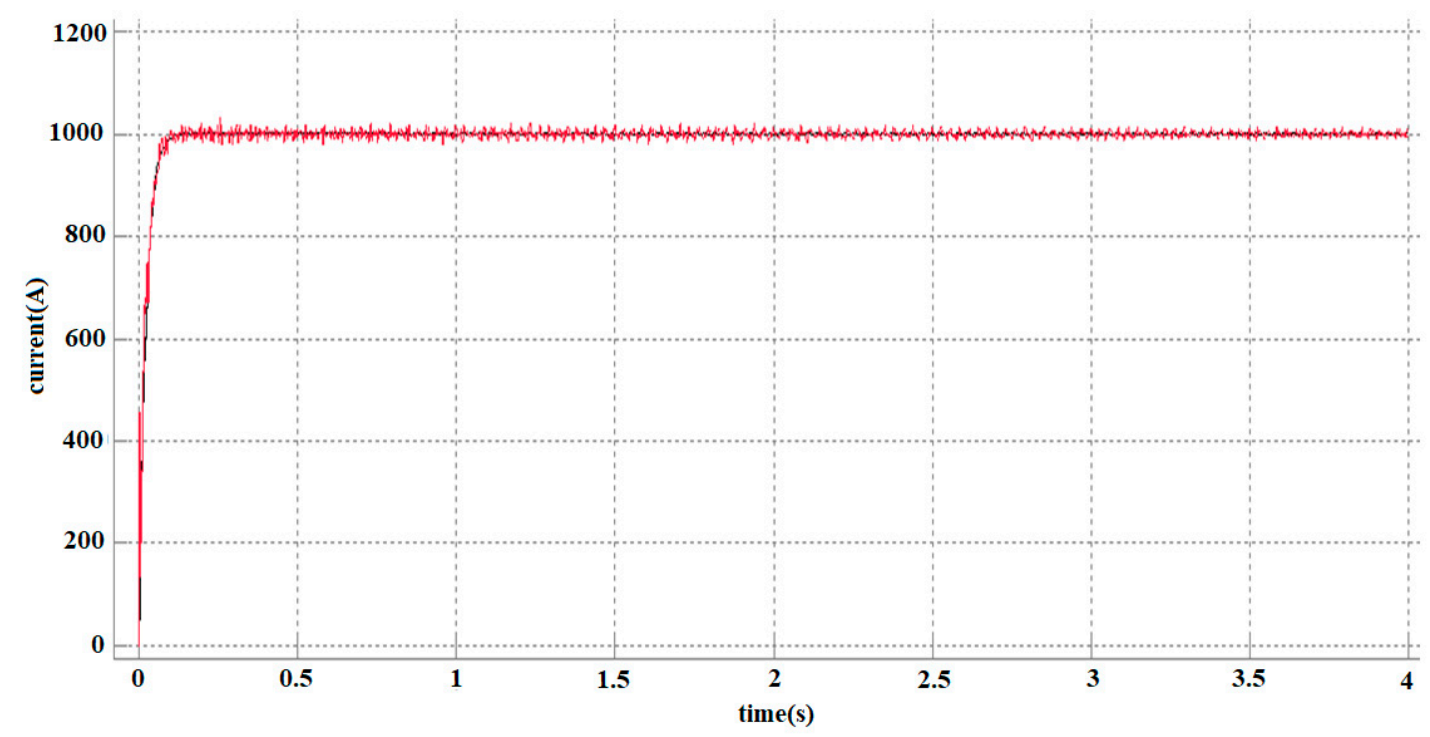

Figure 15. Input-side current tracking of $d$ axis.

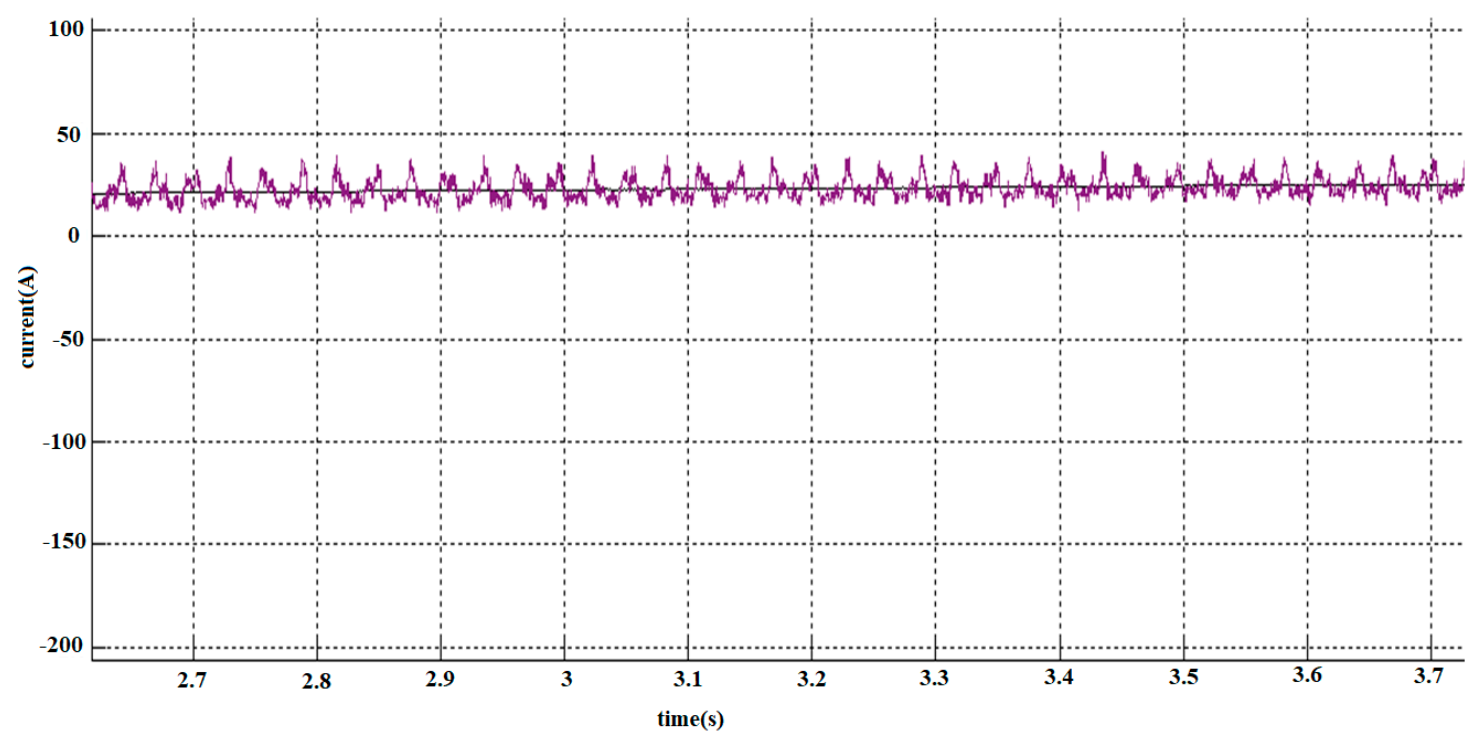

Figure 16. Input-side current tracking of q axis. 


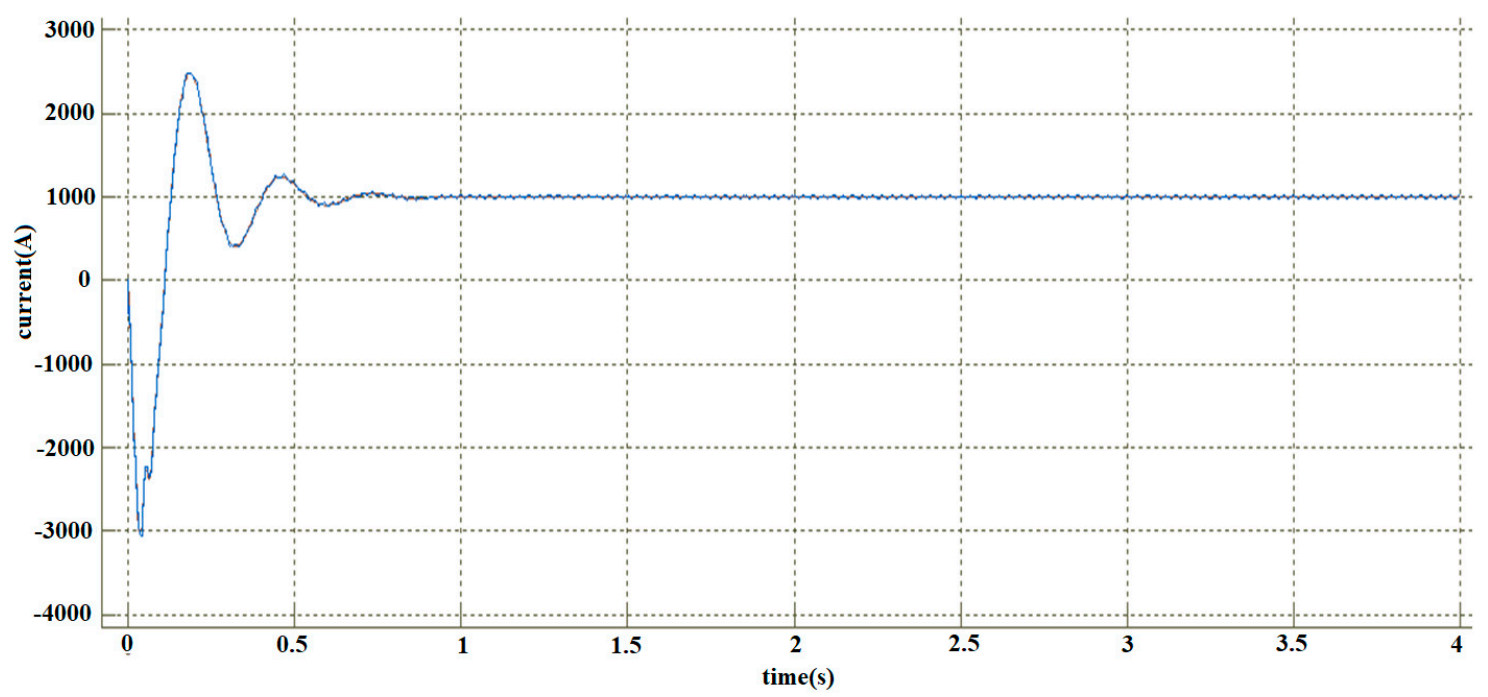

Figure 17. Output-side $\mathrm{d}$ axis current.

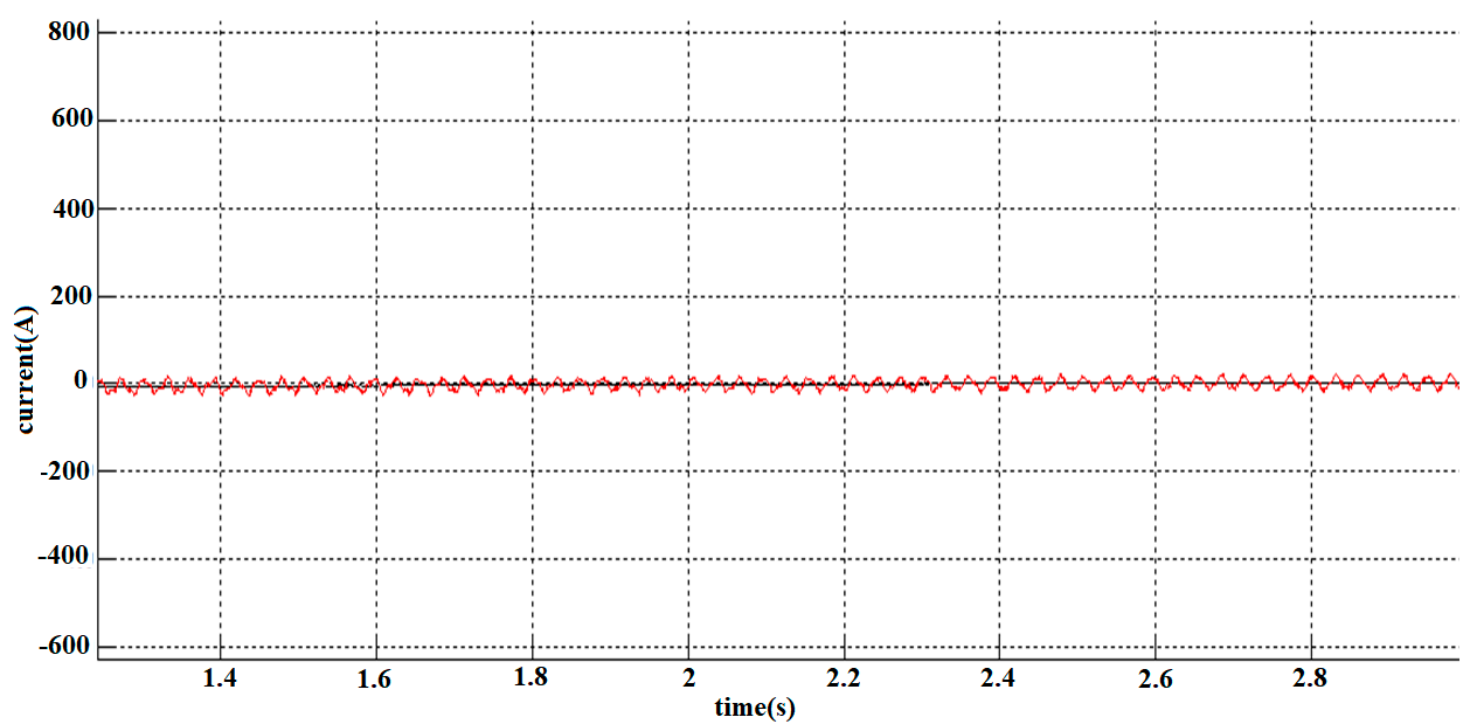

Figure 18. Output-side $\mathrm{q}$ axis current.

Figure 19 shows the PWM waveform of hexverter voltage. It consists of two frequency components, 16 and $50 \mathrm{~Hz}$, which can be seen from the graph. Figure 20 presents the DC voltage tracking, showing that after $0.75 \mathrm{~s}$, the system achieves a steady state at a magnitude of $18 \mathrm{KV}$, side by side the PWM waveform, which also shows a magnitude of $18 \mathrm{KV}$. There are thirteen voltage levels of stair steps, with one zero level; each one is about $3 \mathrm{KV}$, giving a total of $18 \mathrm{KV}$. Each module has a DC voltage of $3 \mathrm{KV}$, which will ultimately give us an AC output voltage of $8.2 \mathrm{KV}$ phase to ground voltage. In order to obtain a linear modulation, the modulation index should be less than 1 ; that is why our output AC voltages are less than the DC voltages. 


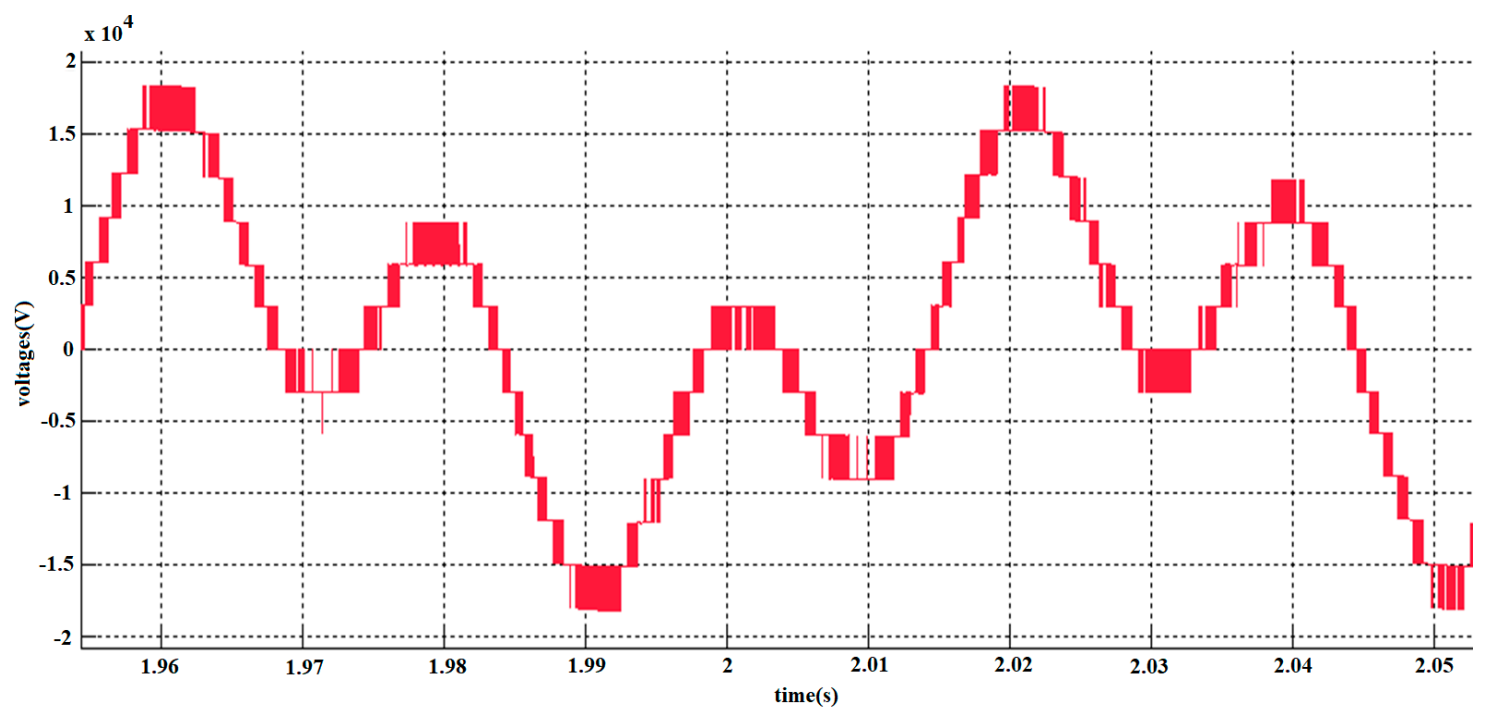

Figure 19. PWM waveform of hexverter voltages.

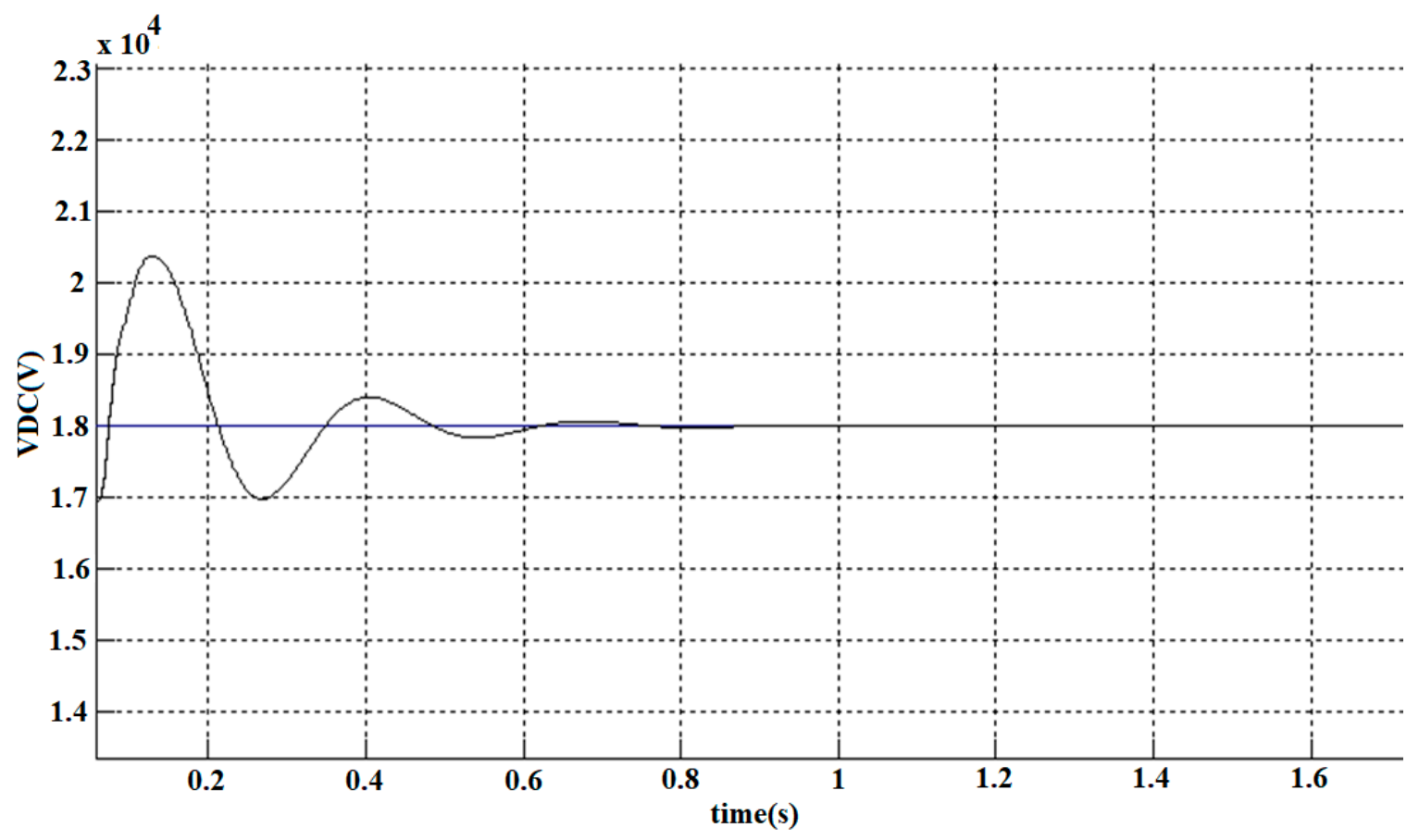

Figure 20. Vdc tracking waveform.

Figure 21 visualizes the comportment of the zero sequence components (zero-sequence circulating current and star point voltage). According to the graph, after $3 \mathrm{~s}$, the voltage is almost zero, and the current is on the negative side, showing a fluctuating response with a magnitude of $120 \mathrm{~A}$, which is much less when compared with other existing control techniques for the same power rating and converter. 


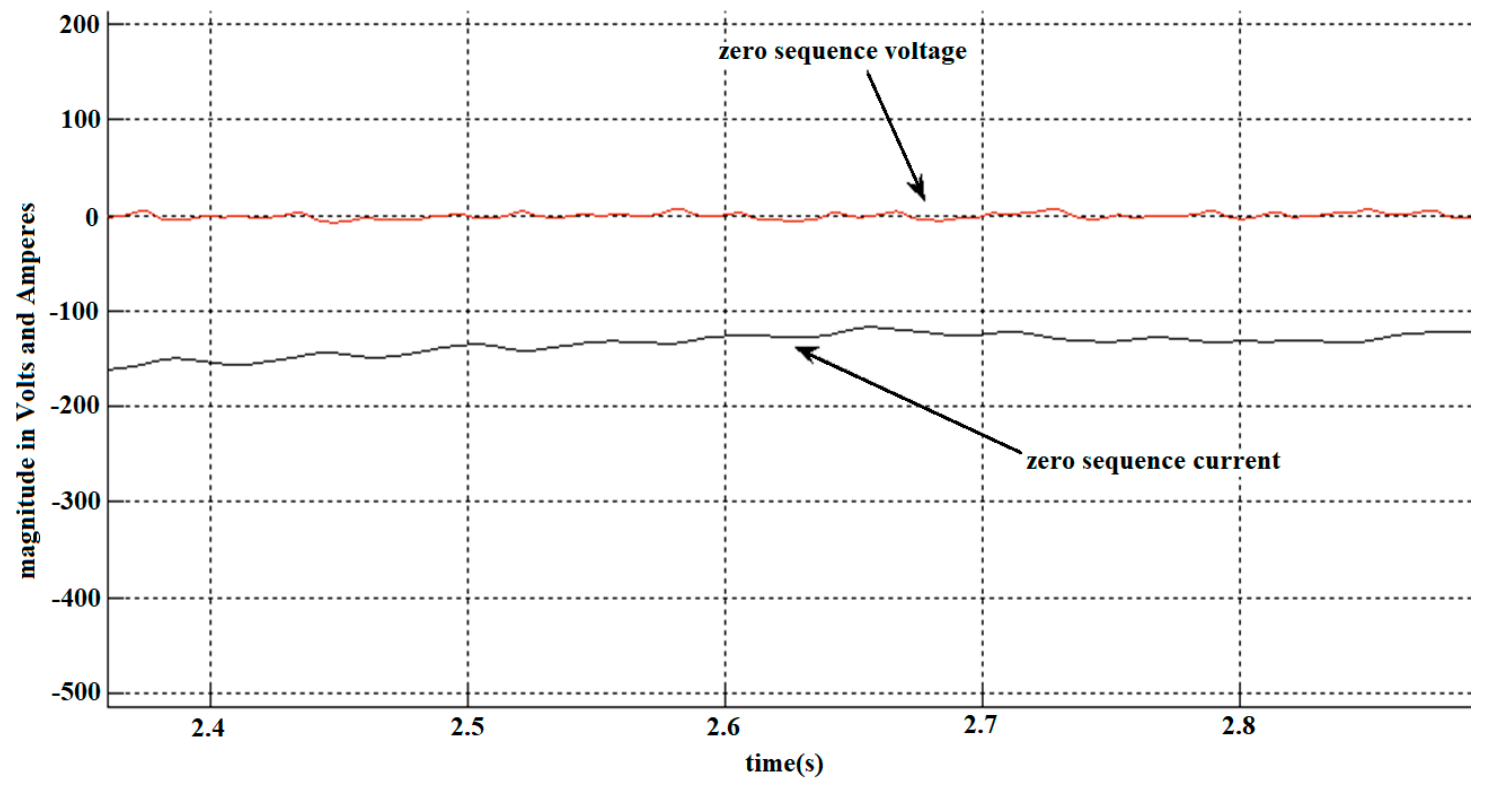

Figure 21. Zero sequence voltage and current waveforms.

\subsection{Wind Farm Simulation Waveforms}

The PMSG-based wind turbine farm gave us $20 \mathrm{MW}$ power at $690 \mathrm{~V}$ to be inserted in the subsea T\&D system through a subsea step-up transformer at $132 \mathrm{KV}$. The simulation results for active and reactive power insertion into the system are shown in Figure 22, along with the terminal voltage, which is $580 \mathrm{~V}$, and current, which is $23.4 \mathrm{KA}$, as per the simulation outcomes shown in Figures 23 and 24 , respectively.

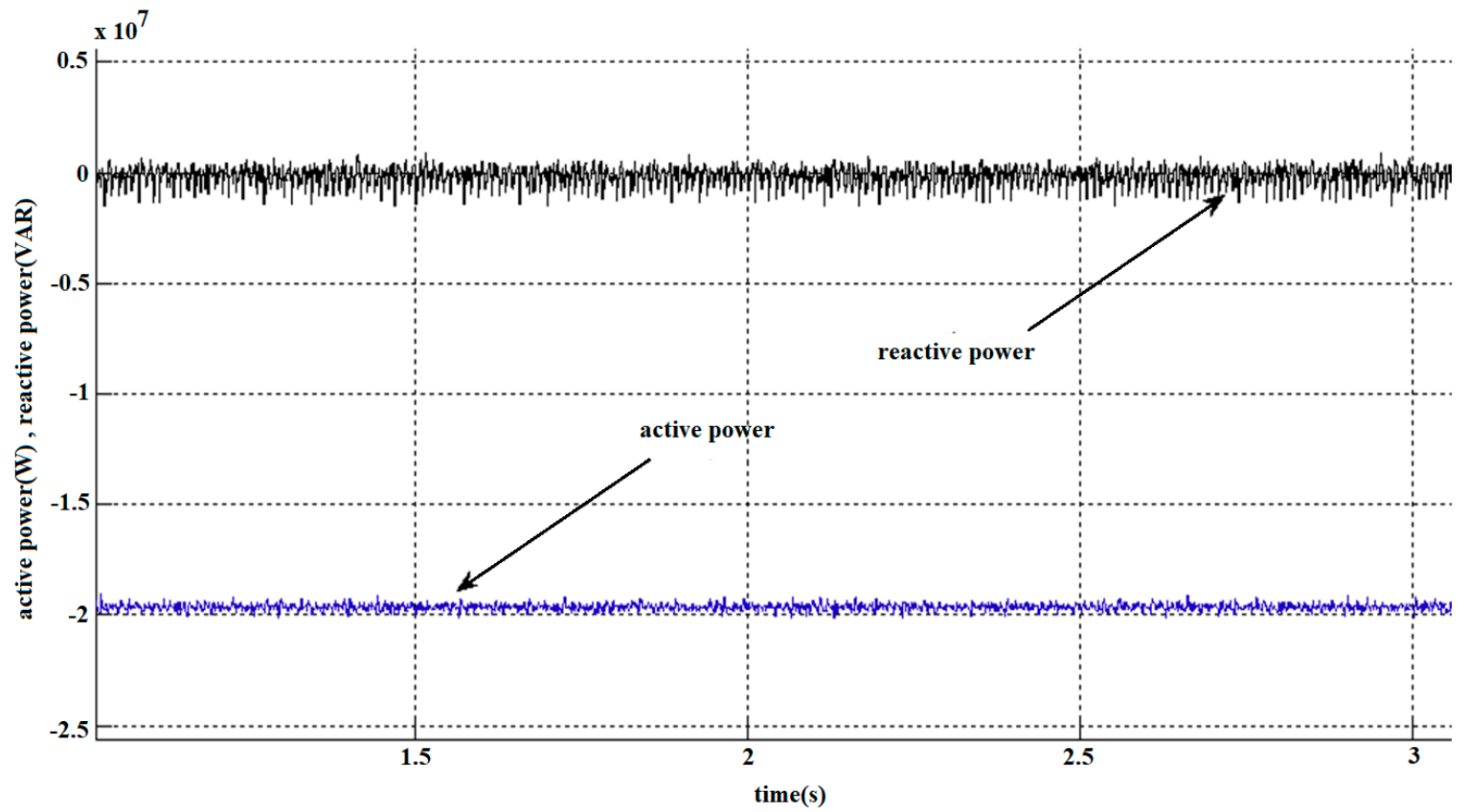

Figure 22. Active and reactive power waveforms of wind farm. 


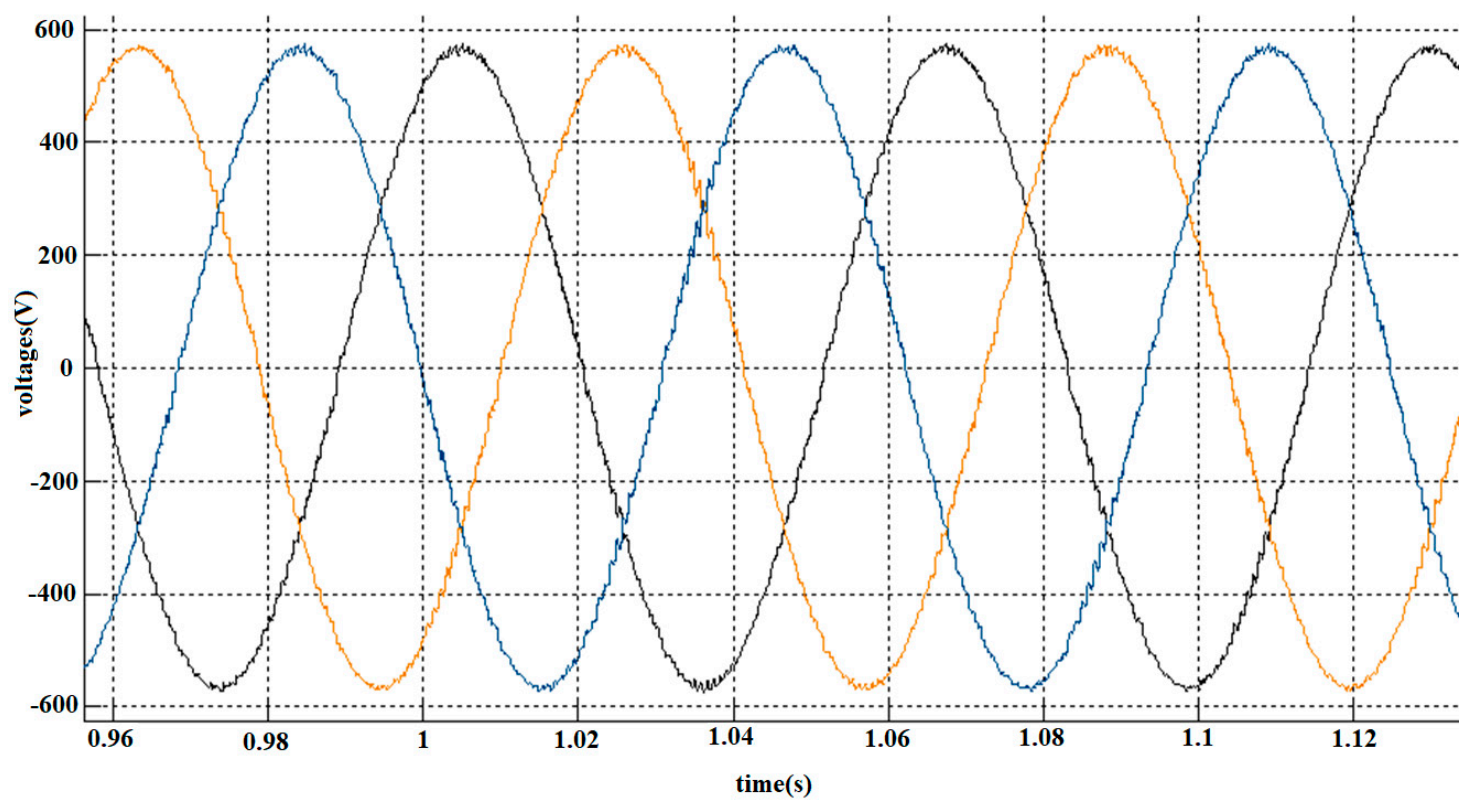

Figure 23. Output voltage waveform of wind farm.

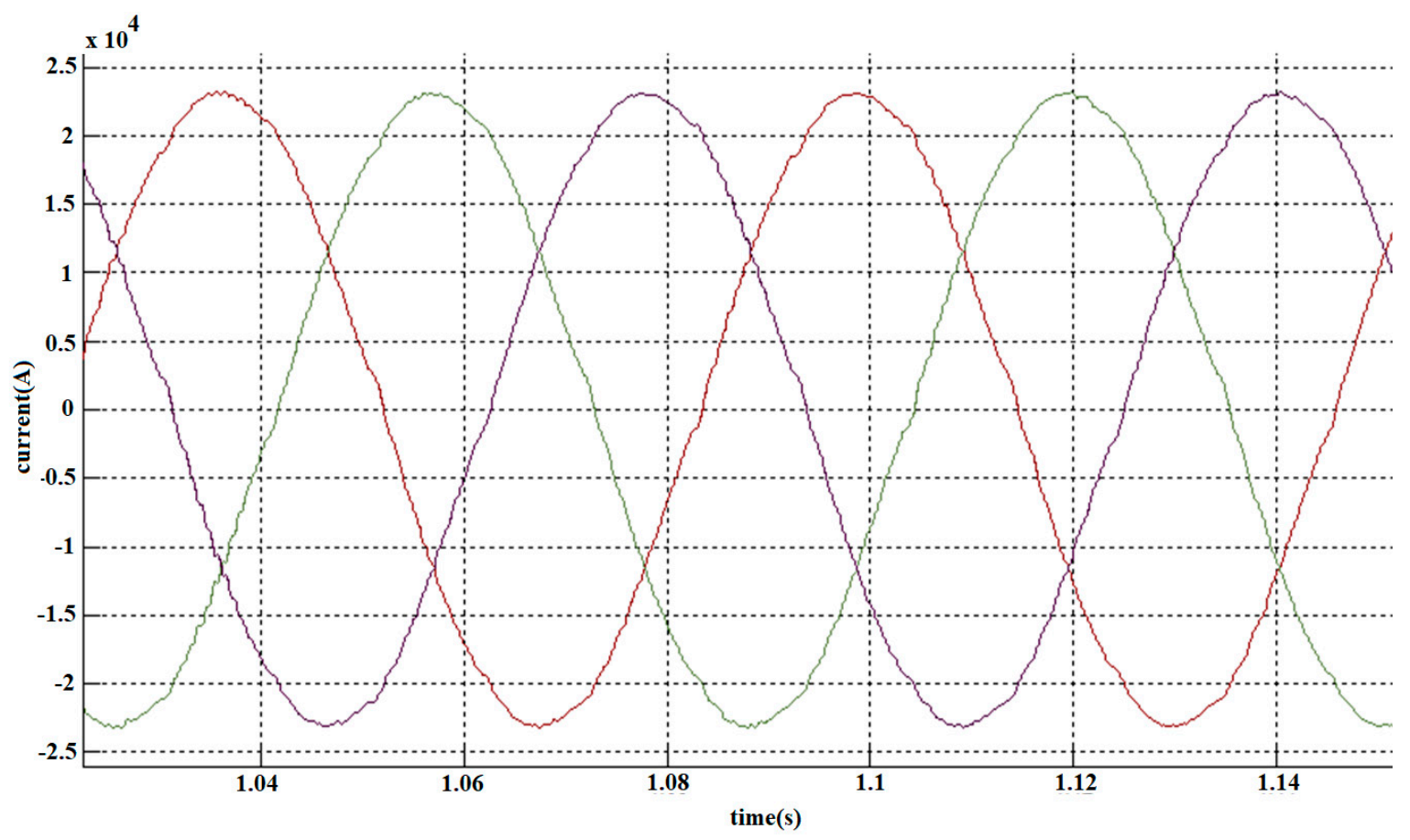

Figure 24. Output current waveform of wind farm.

Then, these voltages are stepped up to $132 \mathrm{KV}$ and transmitted through the $5 \mathrm{~km}$ subsea cable to the main subsea transmission line. The active power is $1.96 \mathrm{MW}$, which is due to the friction losses in the generator, semiconductor devices losses, transmission losses, and the harmonics from the subsea T\&D system. These are the main factors causing active power not to reach $20 \mathrm{MW}$. On the other hand, the reactive power is on the zero axis, with an average value of zero MVAR, as the system is not ideal. Therefore, it can be concluded that the results of our system are acceptably close to reality.

The voltage and current phases are all healthy, and from the point of view of harmonics, current, and fluctuations, the voltage is on the required level, and the current also exhibits smooth behavior very close to the desired values. 
To bring the subsea T\&D system close to reality, in the wind farm control system, some real-time contingencies were added. These include a sudden change in wind speed, resonance due to the long subsea cables, and harmonics fed into the system due to the very heavy LFAC load, i.e., the $5 \mathrm{MW}$ induction motor. The control system for both GSI and MSI are capable of dealing with these problems. These constraints were added as fixed values in the control scheme, and due to the effectiveness of control scheme, the results are close to the real-time results when compared with a $50 \mathrm{~Hz}$ system.

In this subsea system, the wind farm integration is a sub-part of the main research work; as stated in the Introduction, there is a large body of literature available regarding wind farm integration. In this particular case, the wind farm serves as a substitute power source, because it is easy to maintain pure LFAC power without using much conversion. The main research work includes hexverter converter optimization in terms of zero sequence circulating current and its control strategy, which has not been addressed in this way to date.

\subsection{Induction Motor Waveforms Analysis}

In this section, it is verified that the motor speed perfectly achieves its steady-state value (which is $6000 \mathrm{rpm}$ ) in just $2 \mathrm{~s}$. At the start, the motor shows a dynamic behavior where the speed goes decreases and then increases simultaneously, according to the FOC control system. However, for such a heavy-duty motor, the obtained torque is not as good as its speed, but it still has a very good value, which is very near to the reference point, which is $7815 \mathrm{Nm}$, as shown in Figure 25.

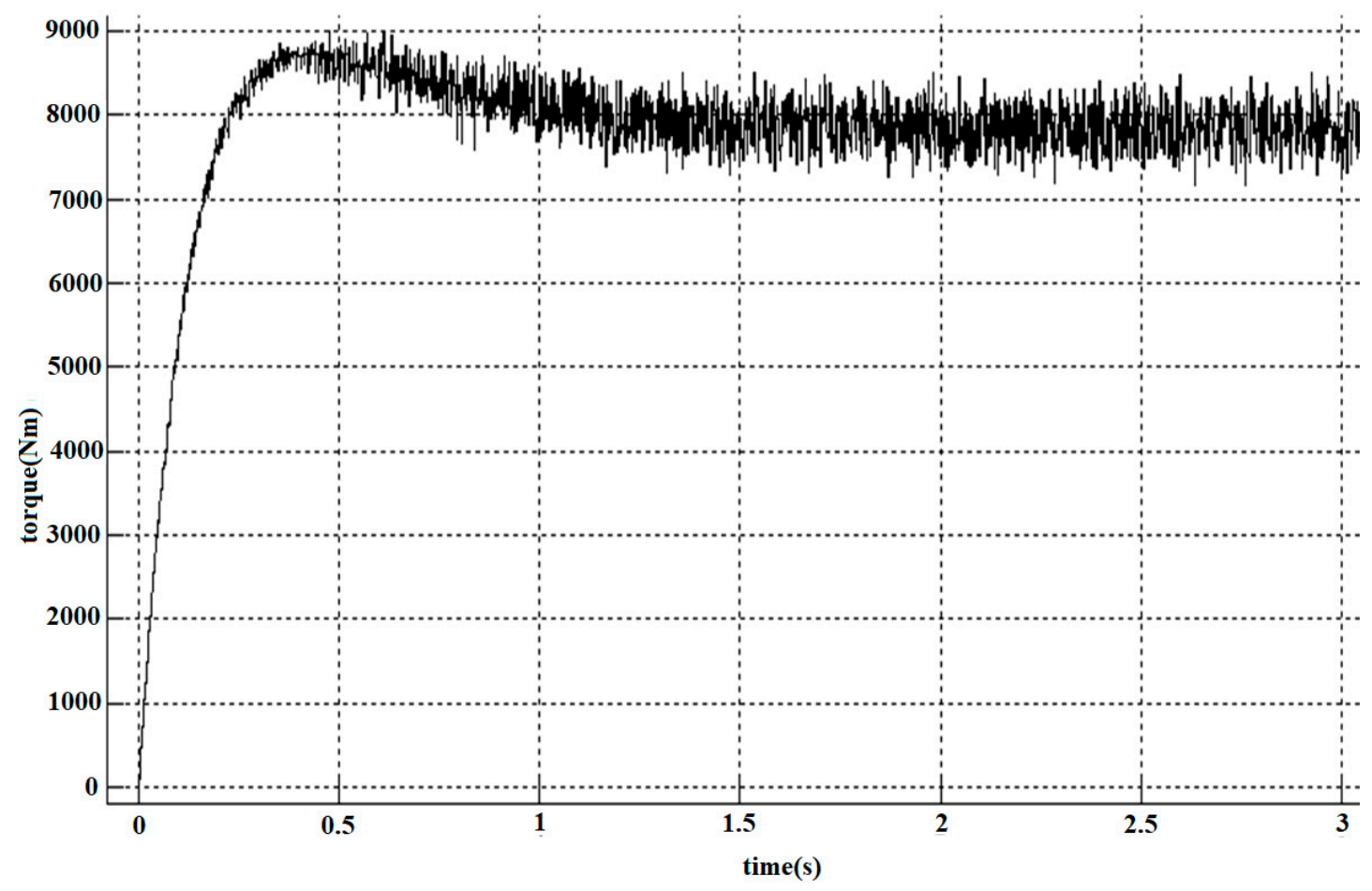

Figure 25. Torque waveform of the motor.

From the results, it can be concluded that the torque and current behavior show good harmony. At the start, when the speed was less, the torque was almost at its peak value. Therefore, due to the high value of torque at a time of $3 \mathrm{~s}$, there will also be high stator and rotor currents, which are $745 \mathrm{~A}$ and $720 \mathrm{~A}$, as shown in Figures 26 and 27, respectively. However, just after $0.5 \mathrm{~s}$, the speed starts to increase, and the torque also tries to stabilize, which ultimately causes the rotor current to become a steady-state value. There are some harmonics in the torque equation, but the average value is almost equal to our desired value, as this system operates undersea at a frequency of $16 \mathrm{~Hz}$. Perhaps, therefore, the system experiences this kind of behavior in the waveforms. To achieve better results, we used a 
zigzag transformer to avoid the current harmonics in the VSD and motor sections, which are able to travel through the system towards the frequency converter, causing its power waveforms to fluctuate over time. Therefore, a zigzag connection with 6 transformers and two rectifiers in the VSD section was set up to achieve perfect isolation and harmonic-free waveforms.

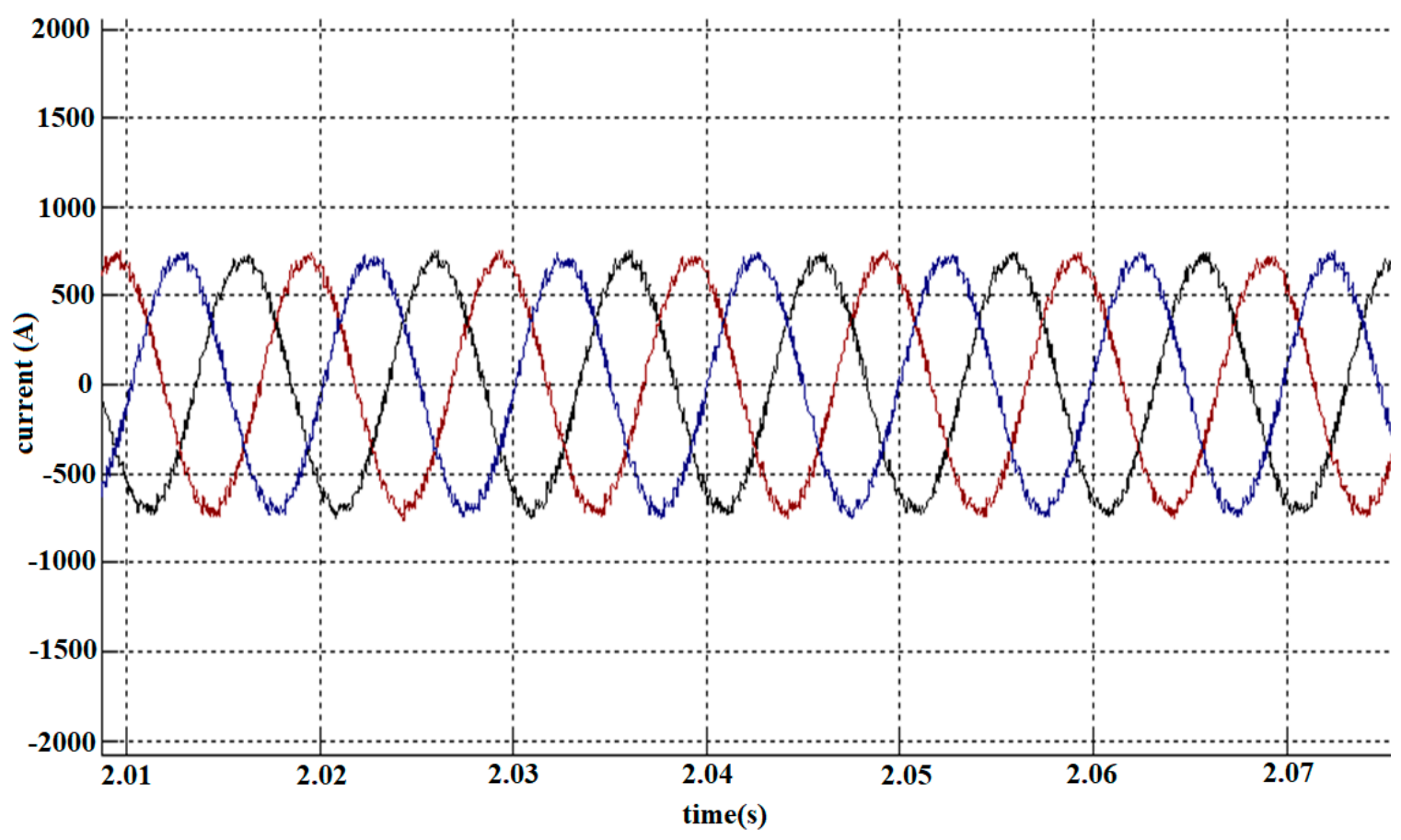

Figure 26. Rotor current of induction motor.

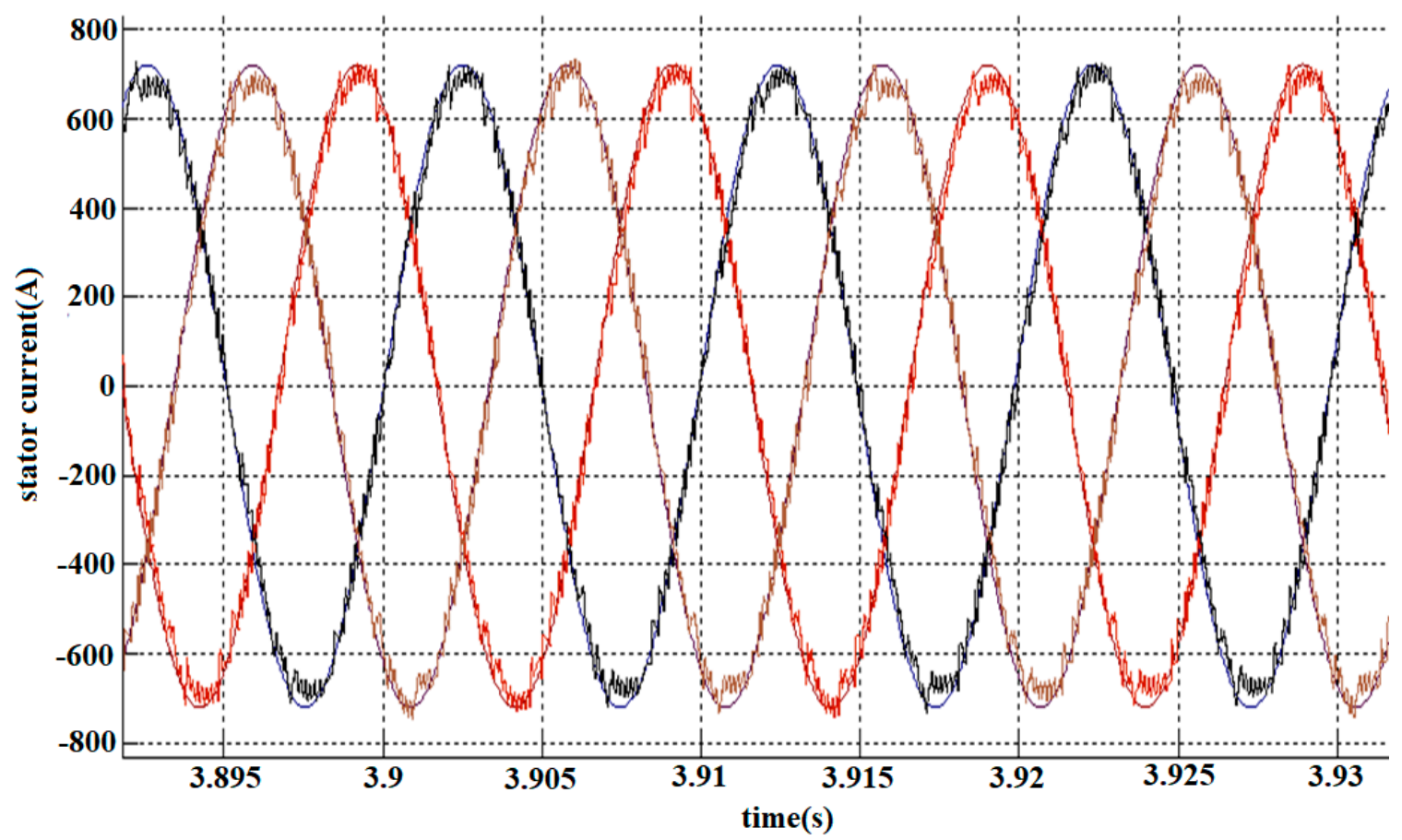

Figure 27. Tracking of stator current of the motor.

A large drop in voltage is caused by the $5 \mathrm{MW}$ induction motor, which represents a relatively high power to be transmitted through the cable, at a voltage level of $6.6 \mathrm{KV}$. It can be seen that there 
is a good match between the real and actual values at steady state. From the speed graph, it can be observed that the motor is started successfully, reaching a rated speed equal to $6000 \mathrm{rpm}$ at $2.4 \mathrm{~s}$, as shown in Figure 28. The active motor power at this speed is almost $5 \mathrm{MW}$, and it operates with a power factor of approximately 0.87 .

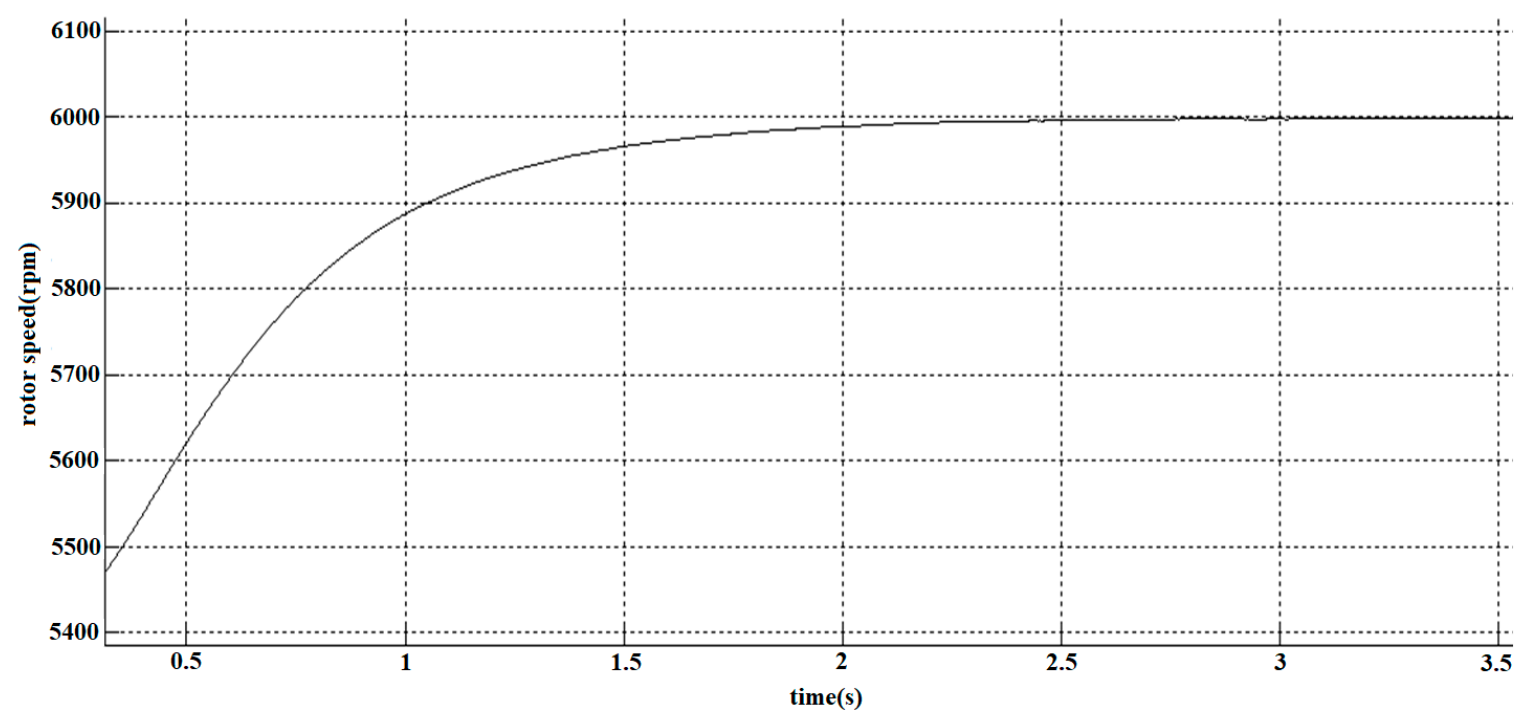

Figure 28. Speed curve of the rotor.

High current is required by the motor to overcome the stiction. However, the majority of the current flowing through the system occurs due to the large torque oscillations produced as the machine approaches the steady state. Once all of the transients have been minimized, the motor is able to operate at the steady state with the required rated current.

The motor's torque oscillate, and reaches a point of equilibrium with the load at $t=3$. Before the time $t$, the torque reaches a value a little higher than its rated value, but after $t=0.5$ seconds, it achieves the steady state. The reason for these oscillations could be the deviations from the sinusoidal flux density distribution around the airgap.

The stator current of the motor in Figure 27 shows the approximate behavior, but is almost equal to the desired value. It can be improved either by implementing a high-quality filter in order to avoid the harmonic current (responsible for the fluctuations in the waveform) or by increasing the steps calculated by the MATLAB, but it would take too much time to run the simulations again. For our subsea T\&D system, the achieved results are considered good enough to continue with.

\subsection{S16 Node Waveforms}

This S16 node was already shown in Figure 2. At this point, another $16 \mathrm{~Hz}$ voltage source was connected, because without this source, the capacitive current would produce huge voltage dips in the system, and due to these dips, power would not be transmitted to the grid. Figures 29 and 30 show the current and voltage waveforms at this point. The voltage level is the same as the hexverter output, i.e., $108 \mathrm{KV}$, but the current is higher, i.e., $135 \mathrm{~A}$. This node receives a total power of $20 \mathrm{MW}$ from the wind farm, and the hexverter output is $30 \mathrm{MW}$, where the load consumes $10 \mathrm{MW}$ (5 MW each from the motor and another RL load), so the remaining active power is transmitted to the grid. Figure 31 clearly shows the $20 \mathrm{MW}$ power at this node, which explains how much active and reactive power is being used by the load and how much is transferred to the grid. The negative sign in the active power waveform simply shows the receiving power. 


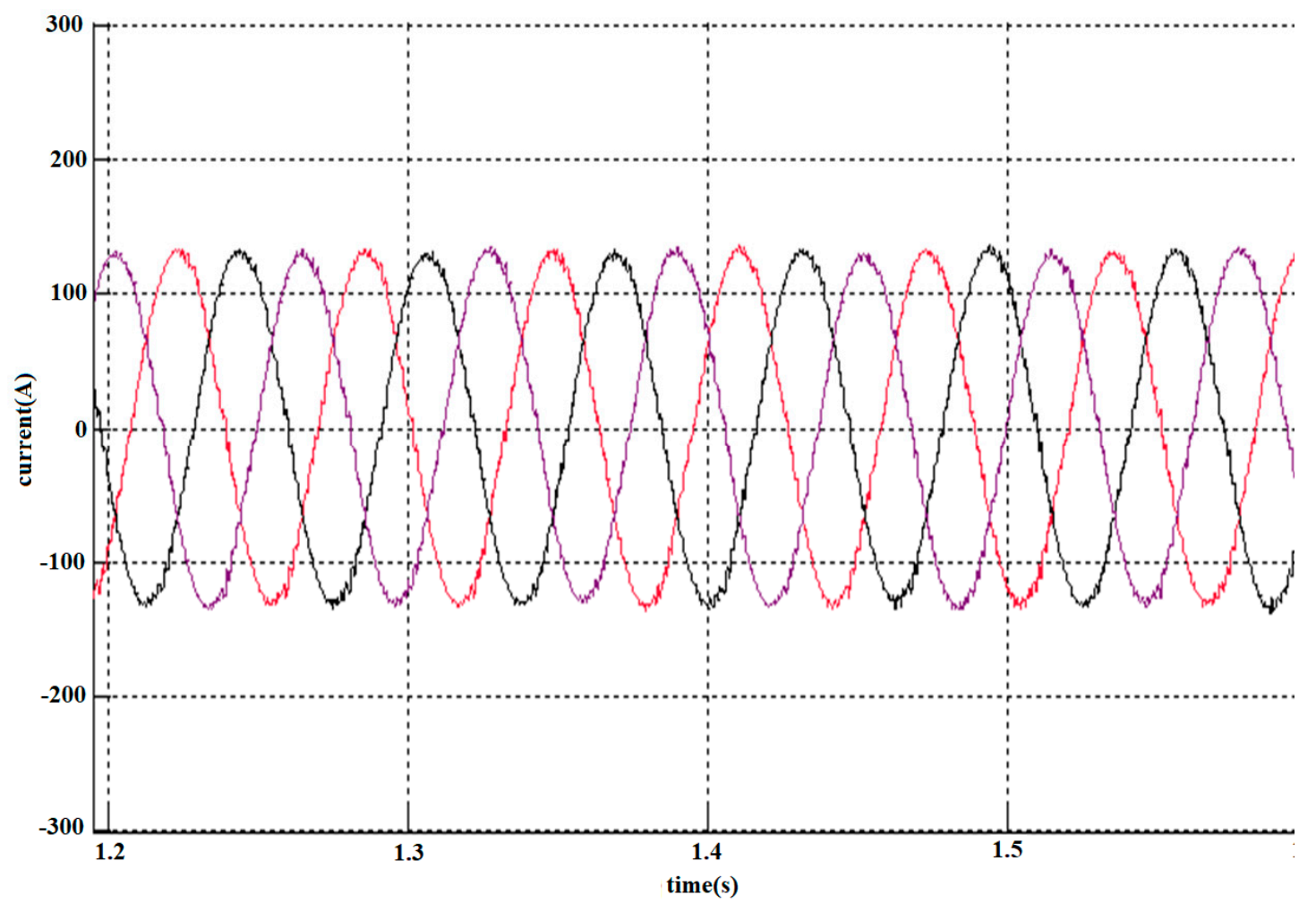

Figure 29. Current at the S16 node.

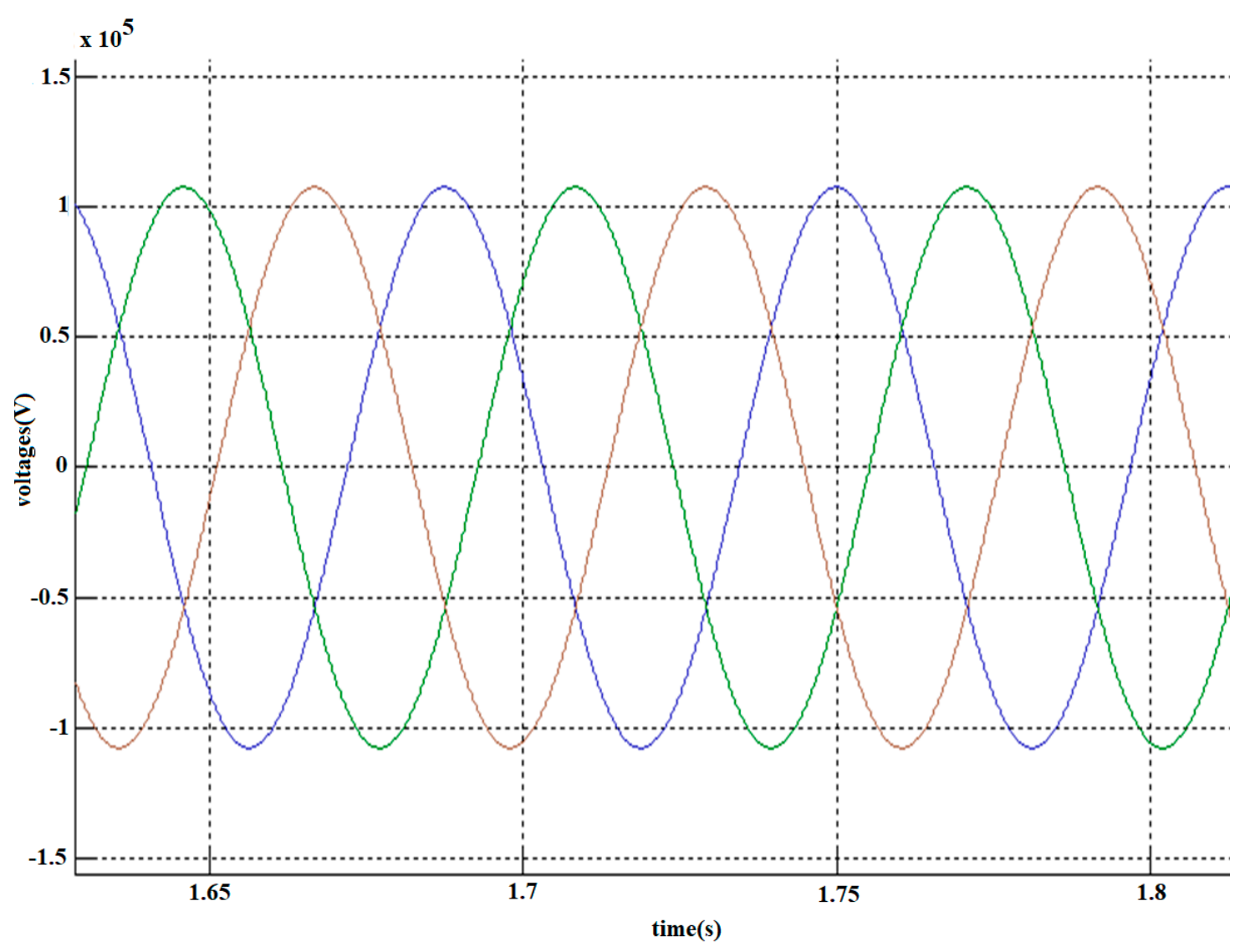

Figure 30. Voltages at the S16 node. 


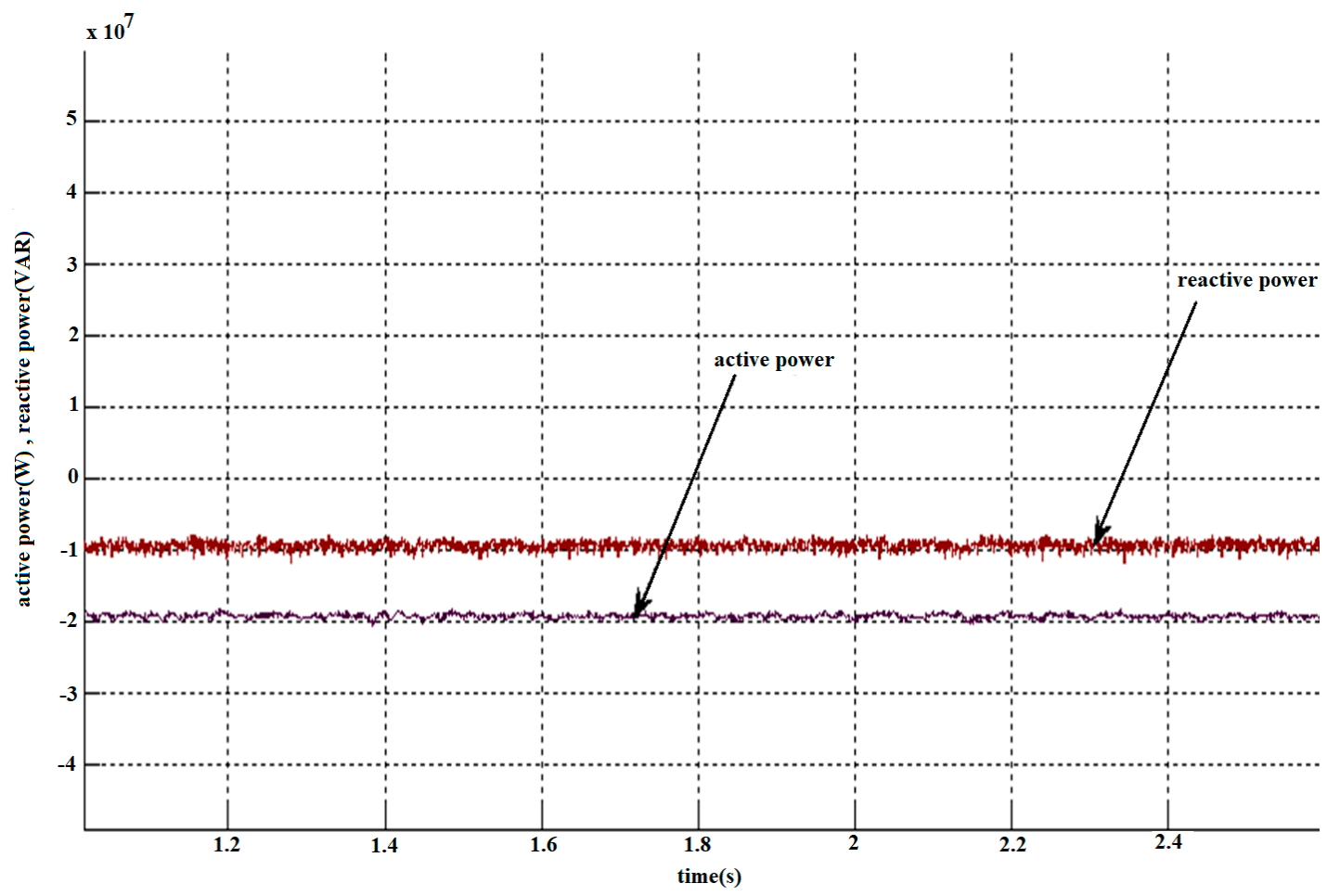

Figure 31. Active and reactive power at the S16 node $(16 \mathrm{~Hz})$.

The reactive power is nearly $10 \mathrm{MW}$, as shown in Figure 31; this power is due to the capacitance in the transmission line, because the transmission line reactance is also dependent on the frequency. The greater the frequency, the lesser the capacitive reactance, which leads to greater reactive current and more reactive power in the system. An excessive reactive current will ultimately limit the current carrying capacity of the cable to transmit the useful current to the load and the grid. It can be observed that we received 10 MAR of reactive power at the S16 node with $16 \mathrm{~Hz}$ frequency, which is three times lower when compared with the $50 \mathrm{~Hz}$ system. Figure 32 shows the reactive and active power of the $50 \mathrm{~Hz}$ system, and it is clear that the 2.95 MVAR reactive power is almost three times greater than, and the $5 \mathrm{MW}$ active power is almost half of, the $16 \mathrm{~Hz}$ system, which proves the effectiveness of the LFAC system. 


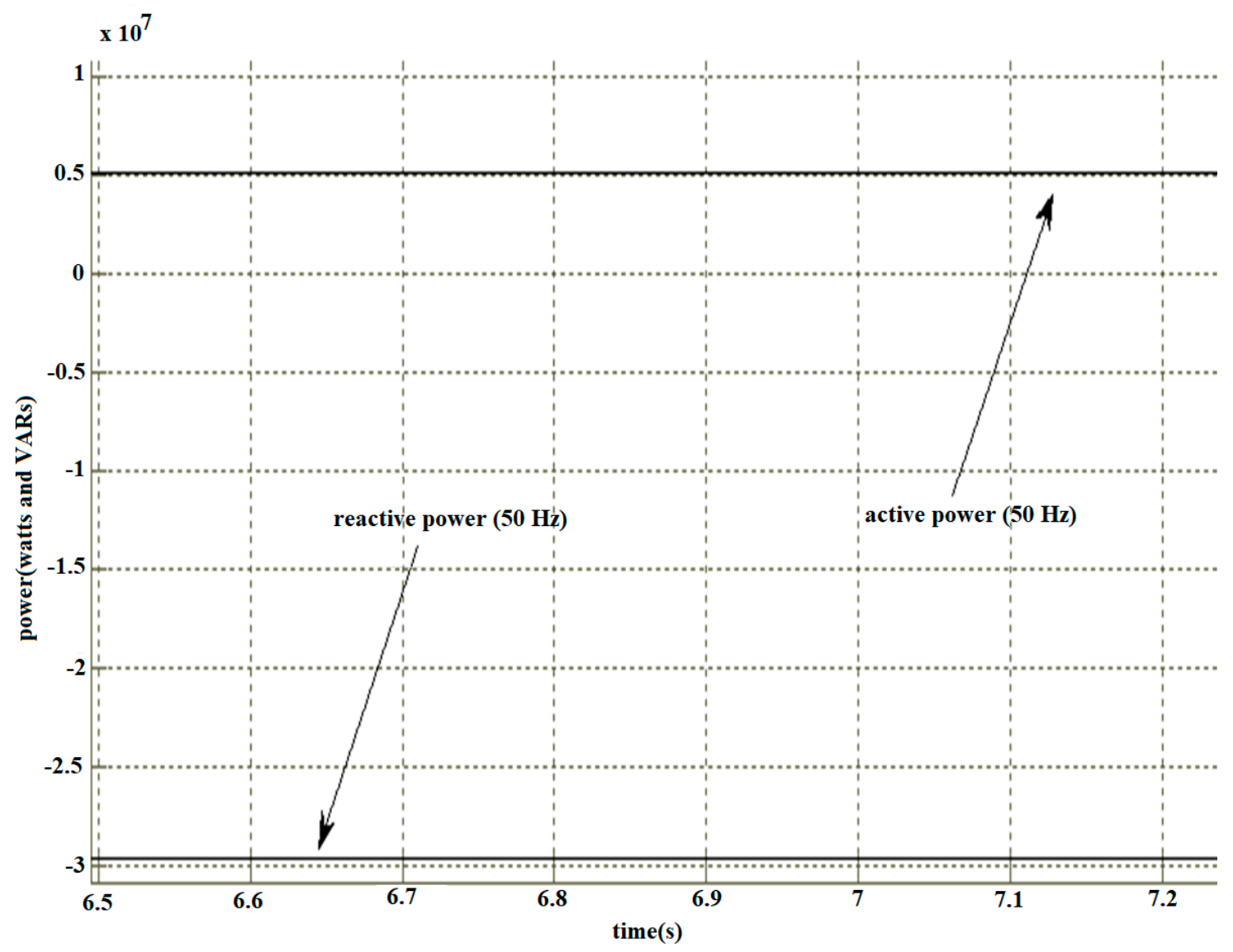

Figure 32. Active and reactive power at S16 $(50 \mathrm{~Hz})$.

\subsection{Transmission Line Waveforms}

This point is located at the end of the subsea transmission line, as was also shown in Figure 2. At this point, the reactive power is zero, and the active power is equal to 9.4 MW, as shown in Figure 33 . Again, the transmission losses and losses in the wind farm system are the factors that affect the active power. Current and voltage have good behavior, as can be verified from Figures 34 and 35, respectively. 


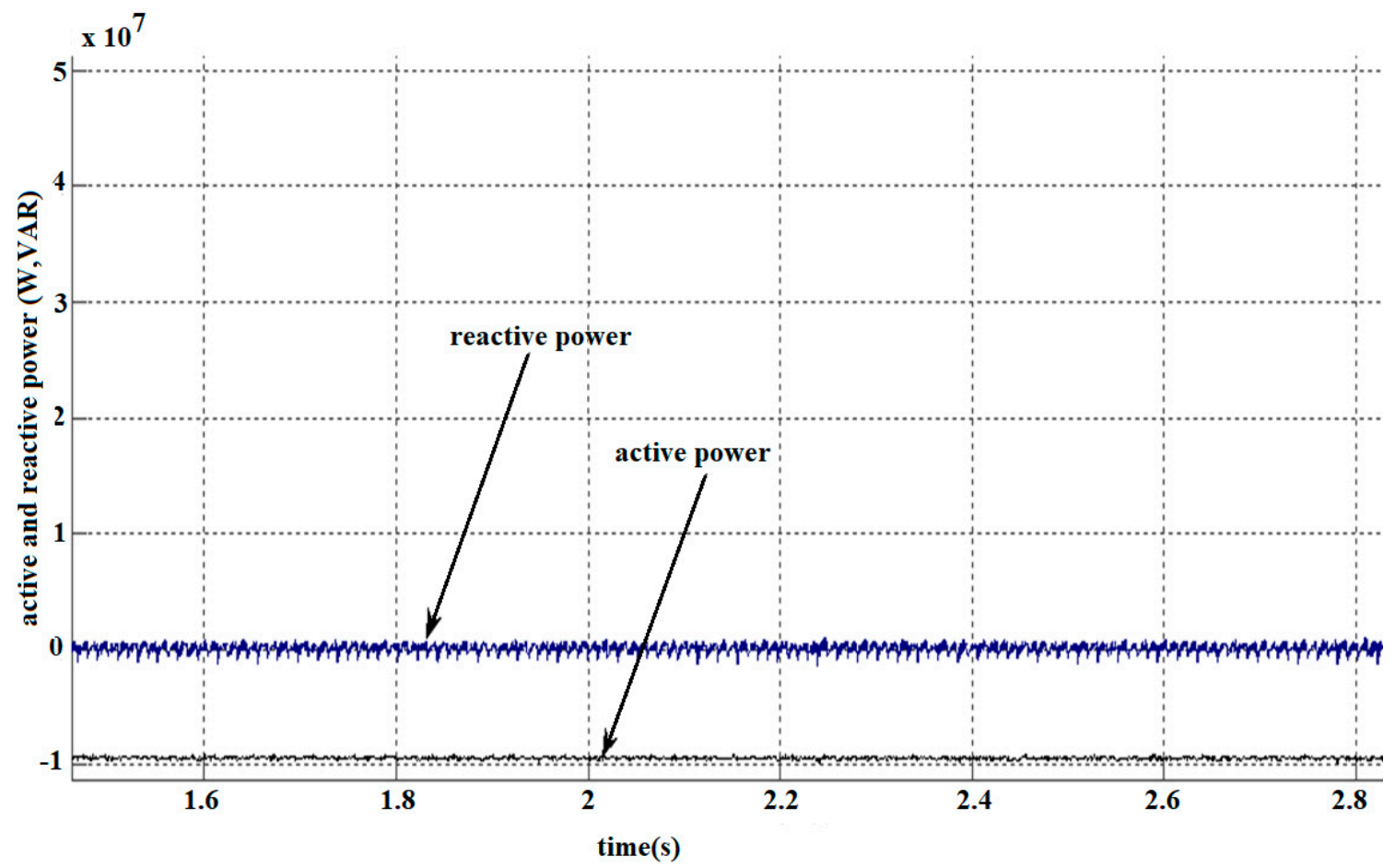

Figure 33. Active and reactive power at the node.

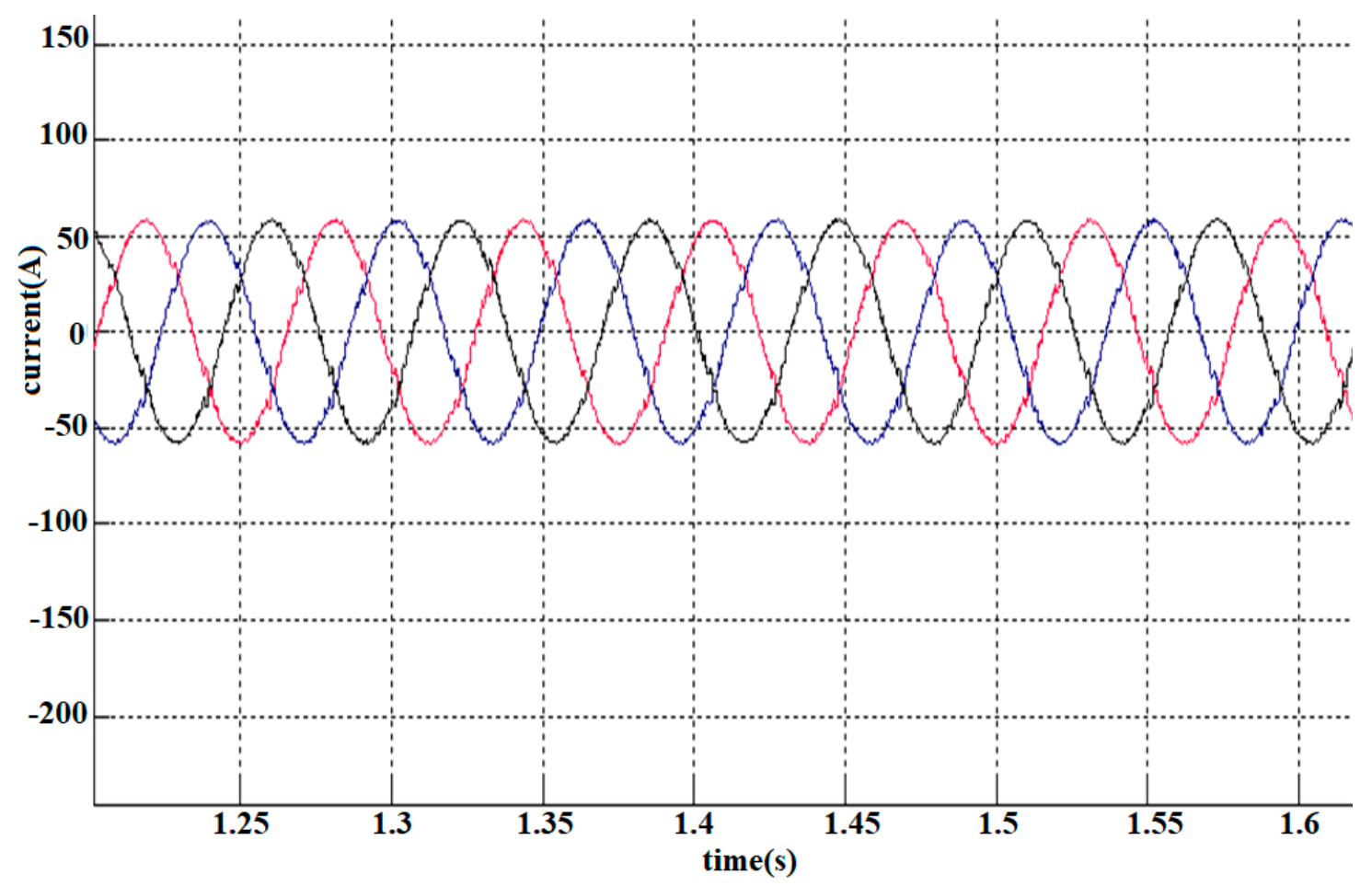

Figure 34. Current waveform across the node. 


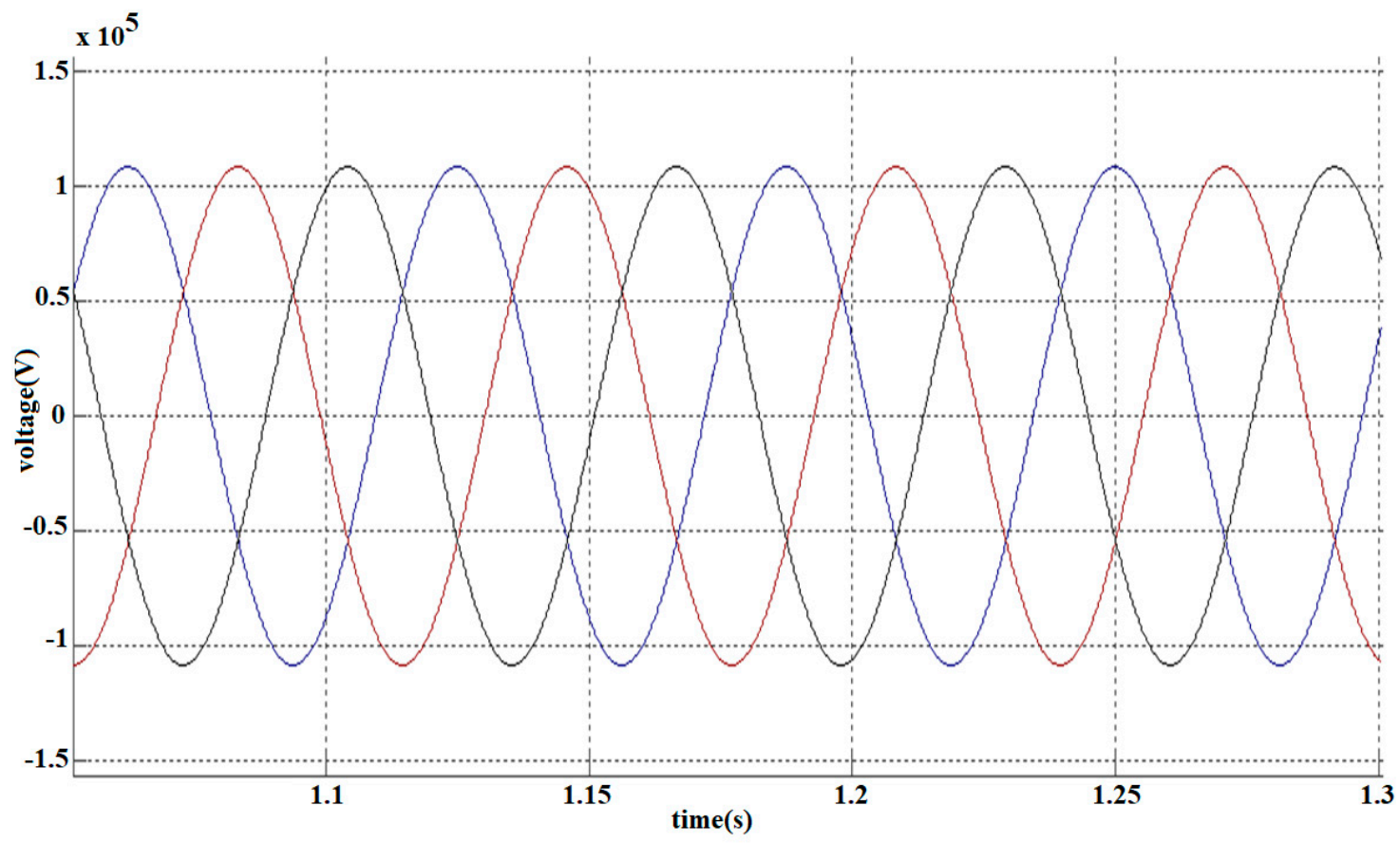

Figure 35. Voltage waveforms at the node.

\subsection{Load-Side Waveforms}

The total load connected to the system was $10 \mathrm{MW}$, including the induction motor and a general-purpose RL load (each one is of $5 \mathrm{MW}$ ). Figure 36 presents the terminal voltage of the load and the load current (the $y$-axis is the magnitude of the voltages and currents in volts and amperes), and Figure 37 visualizes the power used by the load (the y-axis is the magnitude of the active and reactive power in Watts and VAR).

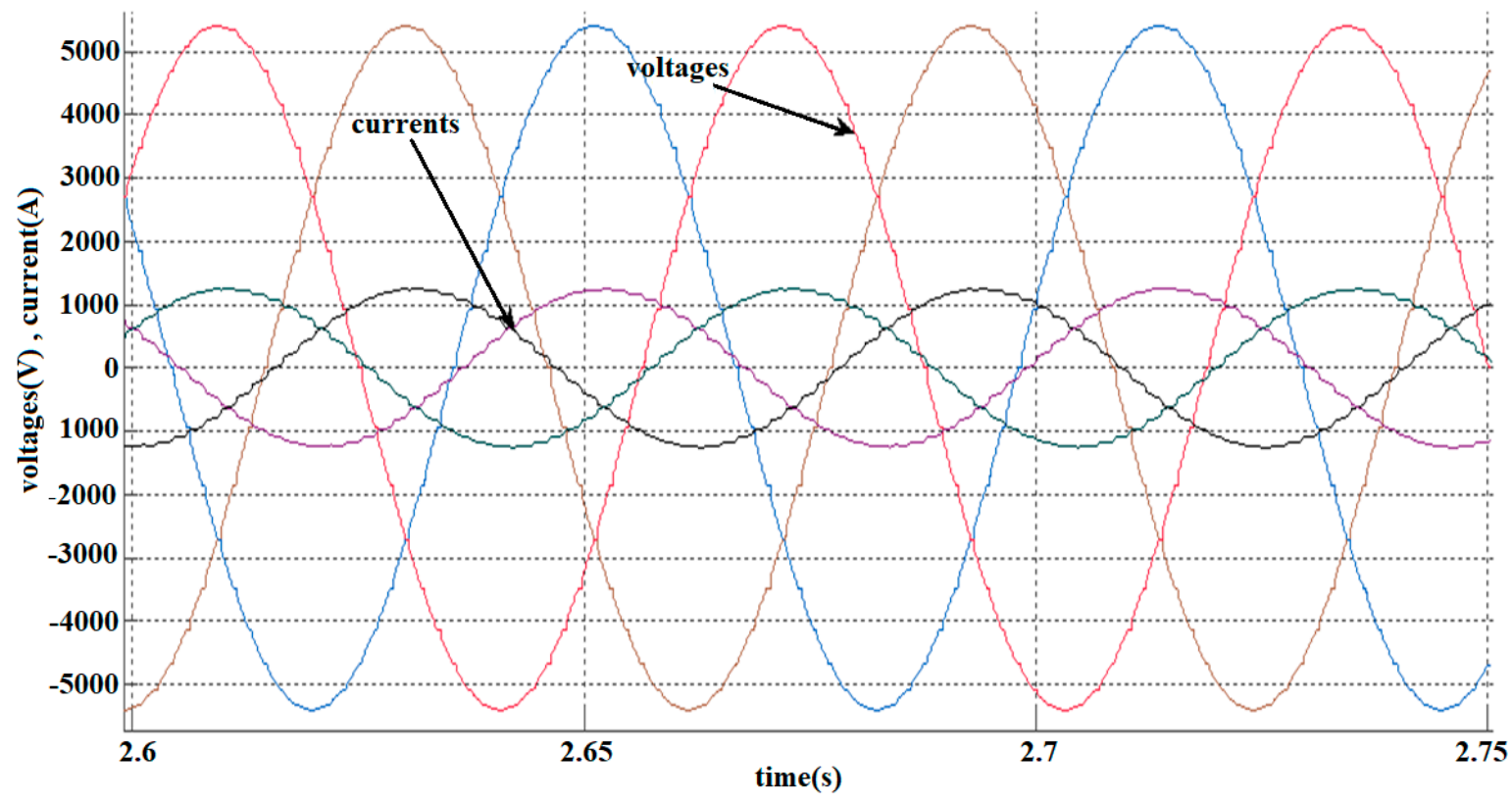

Figure 36. Terminal voltage of the load and load current. 


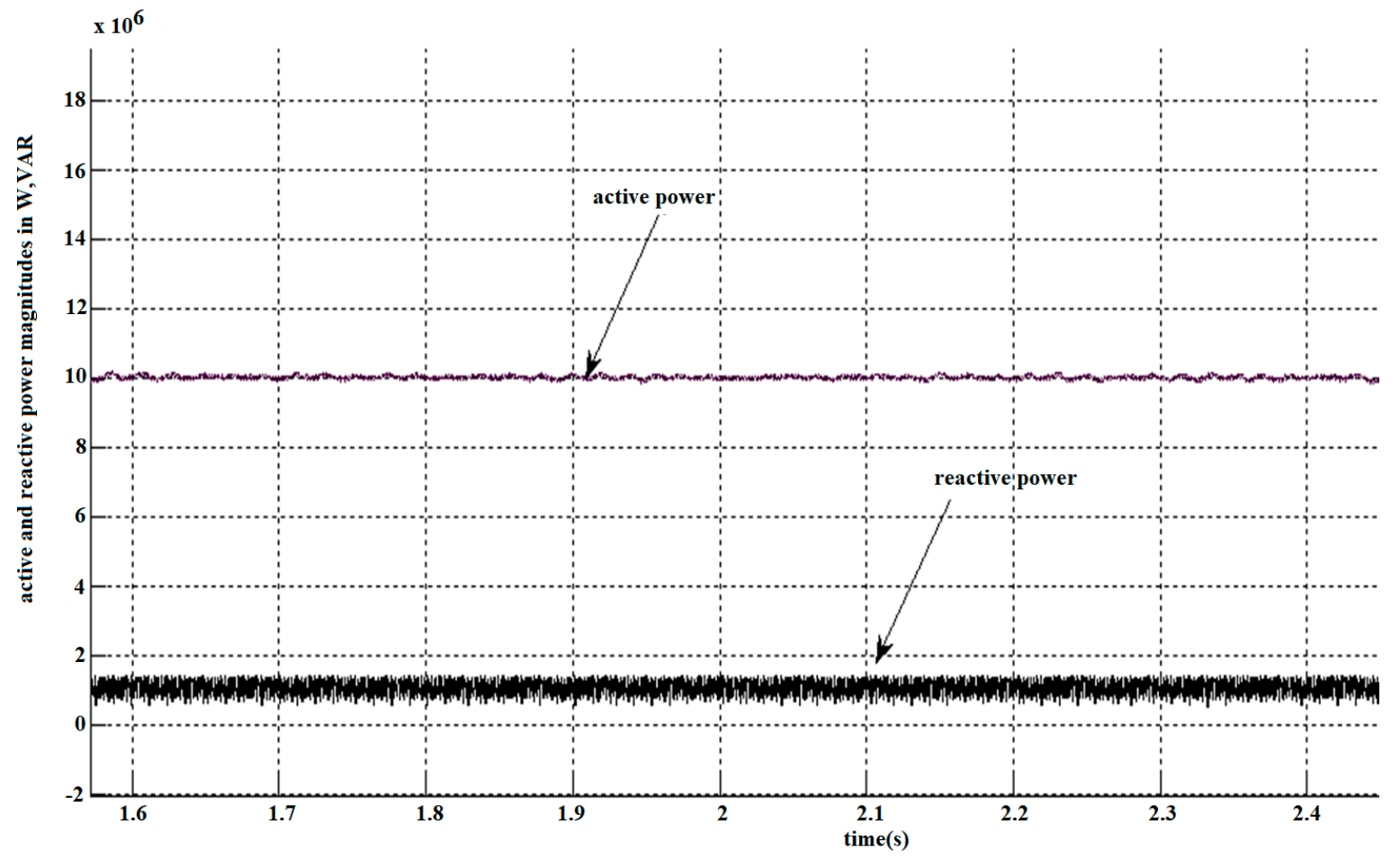

Figure 37. Active and reactive power behavior across the load.

The voltage was approximately $5.45 \mathrm{KV}$ with the current $1.26 \mathrm{KA}$. The active power was $10 \mathrm{MW}$, with almost $1 \mathrm{MW}$ of reactive power; the average of the waveform fluctuation was taken. The overall phase condition was healthy and in the steady state.

Figures 36 and 37 conclude that despite contingencies (added in the wind farm control scheme), harmonics from the high inductive load at the LFAC and the resonance effect in long subsea cables, the obtained results were so close to reality that the desired voltage and power were successfully delivered to the load. The active power graph has a very smooth curve, rather than reactive power. Although the reactive power curve fluctuates, its magnitude is still much smaller, as can be observed from Figure 37.

\section{Conclusions}

The simulation model of the LFAC-based subsea transmission and distribution system was successfully implemented in this work. The system consists of several parts, including a hexverter, which contains a novel control strategy for optimizing its zero-sequence circulating current, subsea power transmission and distribution through subsea cables, a $20 \mathrm{MW}$ offshore wind farm integrated with the system, and a vector control-based variable speed drive to regulate the speed of the $5 \mathrm{MW}$ induction motor. This $5 \mathrm{MW}$ motor further drives the pumps and compressors for oil extraction. Moreover, an RL load of $5 \mathrm{MW}$ was employed in the system for general purpose applications (e.g., lighting, heating and maintenance under the sea). Finally, the results of LFAC-based subsea system were compared with the standard $50 \mathrm{~Hz}$ system. The results indicate that after $3 \mathrm{~s}$, the zero-sequence voltage was almost zero, and the circulating current was at the negative side, showing a fluctuating response that was much lower compared with the other existing control techniques for the same power rating and converter. Finally, the required active power was successfully distributed. However, the reactive power was successfully reduced from $3 \mathrm{MW}$ to $1 \mathrm{MW}$ by using LFAC along with the optimized hexverter.

As this type of subsea system has not been proposed previously, literature comparison is only available for the subparts of the system, i.e., the control strategy of the hexverter for power regulation, the VSD and motor control based on vector control through LFAC, and windfarm integration. 
A comparison of the whole system is, as such, not available. A comparison of subparts was discussed, and the system efficiency was proven through the results, catering to comprehensive control strategies.

Author Contributions: All authors contributed equally to this work. All authors have read and agreed to the published version of the manuscript.

Funding: This research received no external funding.

Conflicts of Interest: The authors declare no conflict of interest.

\section{References}

1. Meere, R.; Ruddy, J.; McNamara, P.; O’Donnell, T. Variable AC transmission frequencies for offshore wind farm interconnection. Renew. Energy 2017, 103, 321-332. [CrossRef]

2. Grotzbach, M.; Schorner, J. CSI-fed subsea cable transmission for motor drive applications. In Proceedings of the 1997 IEEE Industrial and Commercial Power Systems Technical Conference, Philadelphia, PA, USA, 11-16 May 1997; pp. 1-6.

3. Ruddy, J.; Meere, R.; O'Donnell, T. Low Frequency AC transmission for offshore wind power: A review. Renew. Sustain. Energy Rev. 2016, 56, 75-86. [CrossRef]

4. Minette, R.S.; SilvaNeto, S.F.; Vaz, L.A.; Monteiro, U.A. Experimental modal analysis of electrical submersible pumps. Ocean Eng. 2016, 124, 168-179. [CrossRef]

5. Sabel, C.; Herrigel, G. Collaborative Innovation in the Norwegian Oil and Gas Industry: Surprise or Sign of a New Economy-Wide Paradigm. In Petroleum Industry Transformations: Lessons from Norway and Beyond; Taylor \& Francis Group: London, UK, 2018.

6. Axelsson, U.; Ab, V.; Canelhas, A.; Karamitsos, S. Low Frequency AC Transmission on large scale Offshore Wind Power Plants. In Proceedings of the 16th Wind Integration Woekshop, Berlin, Germany, 11-13 November 2014.

7. Ruddy, J.; Chen, J.; Meere, R.; O'Loughlin, C.; O’Donnell, T. Harmonic stability of VSC connected Low Frequency AC offshore transmission with long HVAC cables. Electr. Power Syst. Res. 2018, 162, 220-232. [CrossRef]

8. Domínguez-García, J.L.; Rogers, D.J.; Ugalde-Loo, C.E.; Liang, J.; Gomis-Bellmunt, O. Effect of non-standard operating frequencies on the economic cost of offshore AC networks. Renew. Energy 2012, 4, 267-280. [CrossRef]

9. Meng, Y.; Liu, B.; Luo, H.; Shang, S.; Zhang, H.; Wang, X. Control scheme of hexagonal modular multilevel direct converter for offshore wind power integration via fractional frequency transmission system. J. Mod. Power Syst. Clean Energy 2018, 6, 168-180. [CrossRef]

10. Kala, P.; Arora, S. A comprehensive study of classical and hybrid multilevel inverter topologies for renewable energy applications. Renew. Sustain. Energy 2017, 76, 905-931. [CrossRef]

11. Yuan, C.; Zhou, R.; Tong, M. Topologies and control of low-frequency alternating current for offshore wind farms based on modular multilevel matrix converter. J. Eng. 2019, 2019, 2271-2277. [CrossRef]

12. Baruschka, L.; Mertens, A. A new three-phase AC/AC modular multilevel converter with six branches in hexagonal configuration. IEEE Trans. Ind. Appl. 2013, 49, 1400-1410. [CrossRef]

13. Karwatzki, D.; Baruschka, L.; von Hofen, M.; Mertens, A. Branch energy control for the modular multilevel direct converter hexverter. In Proceedings of the 2014 IEEE Energy Conversion Congress Exposition (ECCE), Pittsburgh, PA, USA, 14-18 September 2014; pp. 1613-1622.

14. Gabriel, R.; Leonhard, W.; Nordby, C.J. Field-Oriented Control of a Standard AC Motor Using Microprocessors. IEEE Trans. Ind. Appl. 1980, IA-16, 186-192. [CrossRef]

15. Hallowell, S.T.; Arwade, S.R.; Fontana, C.M.; DeGroot, D.J.; Aubeny, C.P.; Diaz, B.D.; Myers, A.T.; Landon, M.E. System reliability of floating offshore wind farms with multiline anchors. Ocean Eng. 2018, 160, 94-104. [CrossRef]

16. Zubiaga, M. Power AC Transmission Line. Energy Transm. Grid Integr. AC Offshore Wind Farms 2012, 2, 48-94.

17. Baruschka, L.; Mertens, A. A new 3-phase AC/AC modular multilevel converter with six branches in hexagonal configuration. In Proceedings of the 2011 IEEE Energy Conversion Congress and Exposition, Phoenix, AZ, USA, 17-22 September 2011; pp. 4005-4012. 
18. Karwatzki, D.; Baruschka, L.; von Hofen, M. Optimised operation mode for the Hexverter topology based on adjacent compensating power. In Proceedings of the IEEE Energy Conversion Congress and exposition (ECCE), Pittsburgh, PA, USA, 14-18 September 2014; pp. 5399-5406.

19. Karwatzki, D.; Baruschka, L.; Mertens, A. Survey on the Hexverter topology: A modular multilevel AC/AC converter. In Proceedings of the 9th International Conference on Power Electronics and ECCE Asia, Seoul, Korea, 1-5 June 2015; pp. 1075-1082.

20. Ruddy, J.; Meere, R.; O'Loughlin, C.; O’Donnell, T. Design of VSC Connected Low Frequency AC Offshore Transmission with Long HVAC Cables. IEEE Trans. Power Deliv. 2018, 33, 960-970. [CrossRef]

(C) 2020 by the authors. Licensee MDPI, Basel, Switzerland. This article is an open access article distributed under the terms and conditions of the Creative Commons Attribution (CC BY) license (http://creativecommons.org/licenses/by/4.0/). 